\title{
ENSAYO DE ANÁLISIS COMPARATIVO DE TÉCNICAS, MATERIALES Y TIPOS CONSTRUCTIVOS EN LAS FORTIFICACIONES MEDIEVALES DEL ZENETE (GRANADA)
}

José $\mathrm{M}^{\mathrm{a}}$ Martín Civantos

Universidad de Granada

\section{RESUMEN}

Las diferentes técnicas constructivas, las diferencias en plantas y la estratigrafía muraria de las estructuras emergentes son fuente de conocimiento histórico. Este artículo intenta aportar nuevos datos sobre la evolución de las fortificaciones del Zenete (Granada), a lo largo de todo el período andalusí, poniéndola en relación con el poblamiento e intentando mostrar así los cambios sufridos por la comarca.

PALABRAS CLAVE:

Fortificación, castillo, técnicas constructivas, tapial, mampostería, planta, estratigrafía, poblamiento.

\section{ABSTRACT}

The different construction technics, the different shapes of the buildings and the wall stratigraphy of the emergent structures are materials of knwoledge. This paper try to bring new data about the evolution of the Zenete's 
fortifications (Granada), along the andalusian period, relating this with the settlement and trying to show the changes suffered by the region.

KEY WORDS:

Fortress, castle, construction technics, tapial, mampostería, plant, stratigraphy, settlement.

Es imposible hablar sobre castillos y fortificaciones sin hacer referencia al material que los forma y a la manera en la que fueron construidos. Es esta, sin embargo, una cuestión más complicada de lo que a priori podría parecer. Tal vez porque demasiadas veces se ha asumido a qué nos estábamos refiriendo cuando hablábamos de mamposterías o tapiales, tal vez porque, como muchos otros, es un tema complejo y los estudios sobre técnicas constructivas son relativamente escasos. No pocas veces se ha puesto de relieve su importancia, no sólo como fósil guía complementario o alternativo a la cerámica, sino también social, como resto material del pasado, producto de la sociedad que los creó y que se sirvió de ellos. En forma de fortificaciones, casas, lugares de trabajo, etc., la construcción es imprescindible. Como tal, ocupa un lugar esencial en la Historia social y económica. Como parte de la cultura material del pasado más visible y perdurable, es de suma importancia para la Arqueología: "Pueden estar integrados en el paisaje visible o quedar en el subsuelo. Es más, son fósiles o siguen en uso. La certeza de su presencia viene determinada por el método estratigráfico (...), que nos permite asignarles una cronología. Al tratarse de materiales, que cuentan con una base física y ocupan un lugar en el espacio, están provistos de códigos. Para conseguir su depuración como datos, es decir, para ser objetos analizables desde una perspectiva histórica, es preciso dotarlos de una dimensión temporal"”.

Por supuesto, no es posible ahora hacer un recuento de los estudios sobre este tema, ni pretendemos adentrarnos en el debate entre Historia y Arqueología y Arqueología y Arquitectura. Nuestra pretensión es, únicamente (y no es poco, dado lo complejo del tema), hacer un análisis comparativo (inserto en gran medida en el estudio de los yacimientos), de las distintas

1 Antonio MALPICA CUELLO, "Las técnicas constructivas en al-Andalus. Un debate entre la Arqueología y la Arquitectura", en Técnicas agrícolas, Industriais e Constructivas na Idade Media. Celanova, 8-12 de Xullo de 1996, La Coruña, 1996, pp. 277-336, p. 279. 
técnicas y materiales empleados en la construcción de las fortificaciones analizadas en el Zenete. Para una mejor comprensión, dado el amplio repertorio y los interesantes ejemplos encontrados, nos parece importante detenernos en ellos antes de la descripción realizada a la luz también de los resultados obtenidos en el estudio de la cerámica de prospección y de la documentación escrita. Queremos integrar el capítulo de las técnicas constructivas como uno más dentro de los trabajos arqueológicos e históricos, como fuente de conocimiento, eso sí, siempre que se les dote de una dimensión científica².

En este sentido es fundamental la aplicación del método estratigráfico ${ }^{3}$, pero también el estudio en horizontal de las plantas de los edificios para intentar comprender su lógica y su funcionalidad. Es evidente que los edificios son elementos cuatridimensionales, es decir, ocupan un lugar en el espacio, pero igualmente perduran en el tiempo, con la misma o con otra funcionalidad, o incluso tras su abandono; sufren, por tanto, modificaciones en su diseño original en razón de muy distintas circunstancias. Pueden ser dañados intencionadamente o no y, en consecuencia, deben ser restaurados o parcialmente reconstruidos; puede igualmente cambiar su uso o la formación social que los ocupa y deberán entonces ser adaptados o rehabilitados. No obstante, en cualquier caso, desde su planteamiento original hasta la última de sus modificaciones o su destrucción o abandono, el edificio responde siempre a una lógica, es, por tanto, comprensible a través de las huellas dejadas en sus distintas fases.

En el Zenete andalusí encontramos solamente dos tipos constructivos: la mampostería y el tapial. No obstante, lo verdaderamente interesante son las variantes que dentro de estas dos técnicas van a darse a lo largo de las fortificaciones de toda la comarca y simultáneamente dentro de cada una de ellas marcando distintas fases constructivas o diversas aplicaciones para diferentes funciones. Sin embargo, no siempre es fácil distinguir cada una de estas variantes, a veces por su mal estado de conservación, otras, aunque

2 Un estado de la cuestión así como interesantes elementos para el estudio y el debate en el artículo citado de Antonio MALPICA CUELLO, "Las técnicas..." (supra n. 1).

3 Roberto PARENTI, "Le tecniche di documentazione per una lettura stratigrafica dell'elevato", en Riccardo FRANCOVICH, y Roberto PARENTI (eds.), Archeologia e restauro dei monumenti, Florencia, 1988, pp. 249-279, p. 269. 
resulte paradójico, por su buen estado, ya que los enlucidos no dejan ver el interior ni los elementos constructivos. En ocasiones, el excesivo localismo también dificulta la interpretación adoptando soluciones muy particulares.

\section{MAMPOSTERÍA.}

Es la obra realizada con mampuestos (piedras de mediano o incluso gran tamaño) colocados a mano. La piedra no es escuadrada, aunque si trabajada al menos para poder darle cara y adaptar su tamaño o su forma. Hay además que organizarlas medianamente para que encajen unos mampuestos con otros, o bien añadirle ripios de pequeño tamaño (a veces ni siquiera de piedra sino fragmentos cerámicos o escoria). También puede concertarse en hiladas, en cuyo caso los mampuestos deben adaptarse a su disposición en horizontal, en vertical o en espina, y/o encintarla con una o varias verdugadas de lajas o ladrillos. La mampostería puede igualmente servir de relleno de cajones de ladrillo. Por último, la unión de los mampuestos se hace mediante mortero de cal más o menos rico, con tierra o dispuestos a hueso o piedra seca. En su acabado exterior puede dejarse vista o rejuntarse con mortero de cal que le dará mayor consistencia; un rejuntado que puede ser más grueso hasta llegar a ser casi un enfoscado total del muro que solo deje ver parte de los mampuestos a través de un llagueado en vitolas. Y es posible también que llegara a enfoscarse por completo y enlucirse. Los enfoscados y revestimientos pueden ofrecer una imagen desvirtuada del interior del aparejo y ser una forma de engaño o disimulo. A veces son también decorados con incrustaciones de escorias o mineral o con incisiones.

En cualquier caso, la construcción se hace normalmente con materiales disponibles in situ o en el más inmediato entorno y de acuerdo con las posibilidades de uso. La mampostería se emplea para cualquier tipo de construcción: desde las paratas para los bancales (normalmente en piedra seca), hasta fortificaciones, pasando por viviendas. Es fundamental también como cimiento y basamento del tapial, que nivela para la colocación del encofrado y aísla de la humedad. Tradicionalmente la mampostería ha sido utilizada independientemente de las épocas, aunque parece generalizarse su uso en las fortificaciones de los siglos finales de la Edad Media ${ }^{4}$.

4 Antonio MALPICA CUELLO, “Las técnicas...” (supra n. 1), pp. 299-301. 


\section{TAPIAL o TABIYYA}

Tal vez sea la técnica más característica y significativa de la construcción andalusí (fig. 2). Básicamente consiste en formar cajones prismáticos de encofrado con varias tablas dispuestas en horizontal y unidas por traviesas verticales de madera llamadas costales o costeros. En sentido horizontal y perpendicularmente a las tablas se disponían tablillas llamadas agujas que podían o no atravesar el cajón de lado a lado y servían para darle rigidez al encofrado en unos casos o simplemente para sujetarlo a la obra. En este último supuesto se utilizan cuerdas de esparto para dar rigidez y evitar que el cajón se abra al verter el material. Es aquí, en la sujeción de los cajones y disposición de las agujas, donde encontramos mayor número de soluciones y variantes constructivas adoptadas localmente y, por ahora, imposibles de adscribir geográfica o cronológicamente, si es que tal sentido pudieran tener.

Normalmente en las murallas, con espesores medios de $1,30 \mathrm{~m} \mathrm{y}$, sobre todo en las torres, las agujas no atraviesan todo el muro. Suelen disponerse embutidas en el cajón inferior en el que se practica una roza con lo que se evita realizar ranuras en las tablas, no siempre adecuadas a las dimensiones de las agujas, que suelen variar. Para evitar entonces que, al sujetar el encofrado, las agujas se levanten por el peso, estas se pueden sujetar poniendo encima varios mampuestos gruesos y/o una pella de yeso que fragua rápidamente. También se pueden sujetar clavando la aguja con cuñas o clavos al cajón de abajo. Para dar rigidez al encofrado es posible utilizar varias fórmulas: se puede, mediante cuerdas, amarrar los costales que sobresalen por la parte superior e inferior de las tablas. Las cuerdas pueden atravesar todo el ancho y atarse de costal a costal (así sucede siempre en la parte superior) o pueden atarse al clavo o la cuña que sujeta la aguja al cajón inferior, cuya función entonces es sólo la de sostener el encofrado. De no usar cuerdas se deben sujetar las agujas a los costales o las tablas con cuñas o clavos.

Nos quedarían entonces solo por ver dos elementos no siempre presentes: de una parte las cruces de S. Andrés, agujas dispuestas en diagonal para dar también rigidez al cajón y los costales vueltos hacia el interior, que dejan su huella semicircular en negativo sobre el mortero y que suelen rellenarse después por fragmentos de ladrillo y mortero y posteriormente enlucirse. Estos no son sino resultado de poner el encofrado de un lado u otro para evitar que, por efecto de la humedad, las tablas se comben. Hay así 
ejemplos en los que el encofrado se realiza con un costal hacia cada lado y se va cambiando de posición para forzar los maderos y que no se curvens.

Los lados menores del encofrado quedan también cerrados. En el primer cajón con tablas en ambos extremos, en el resto utilizando el lateral del anterior como cierre, por lo que podrá incluso distinguirse cuál de los dos ha sido construido primero. Las agujas y mechinales para el andamiaje se parten y quedan embutidos en la obra, siendo posteriormente tapados con mortero y enlucido todo el conjunto para evitar el deterioro de la obra y el escalo en el caso de las fortificaciones.

Queda abierta la parte superior del encofrado por la que se vierte el mortero en capas sucesivas llamadas tongadas que son apisonadas antes de verter la siguiente. En su composición se emplean cal o yeso, tierra, grava, piedra y material reutilizado como fragmentos cerámicos, escoria, etc. En función de los componentes o de la disposición de estos, el tapial puede adoptar diversas variantes, en teoría muchas, y que nosotros agrupamos en:

\section{Tapial de tierra:}

El mortero esta compuesto fundamentalmente de tierra con una proporción variable de cal, desde su casi ausencia hasta una cantidad relativamente significativa que le da mayor dureza y lo asemeja al hormigón. El material es y se reparte de forma homogénea en el cajón.

\section{Tapial hormigonado:}

Realizado con hormigón, es decir, mortero rico en cal, con abundante grava de mediano tamaño y gran dureza. El material es y se reparte igualmente de forma homogénea en el cajón. Normalmente es el usado en los aljibes, pero aquí con una variante técnica, sin cajones, realizando el encofrado en una sola vez para evitar las filtraciones de agua a través de los huecos de las agujas y las juntas. Es el más duro y complejo de los tapiales por la cantidad de cal y trabajo invertido en la preparación de la grava.

\section{Tapial de cal y cantos o de calicantos:}

Su principal característica es la presencia de una significativa proporción de mampuestos de gran tamaño formando tongadas, mientras que

5 Fermin, FONT y Pere HIDALGO, El Tapial.Una tècnica constructiva millenaria, Castellón 1990, pp. 50-51. 
su mortero puede contener una proporción variable de cal. En este caso, las grandes piedras lanzadas desde cierta altura realizan la labor de apisonado. La piedra normalmente es la del terreno. Al exterior, el mortero queda liso ocultando los mampuestos pero, en caso de perder la capa exterior, el tapial muchas veces sólo se distingue de la mampostería por la presencia de agujas (fig.3).

\section{Tapial calicastrado o de cal y costra:}

En el las pellas de cal o ricas en cal se colocan siguiendo las tongadas en la parte exterior del cajón, junto al encofrado, de manera que se forme una dura corteza capa a capa que se va adelgazando hacia el interior del cajón hasta desaparecer, dejando paso a un relleno muy pobre en cal, casi imposible de distinguir en la mayoría de las ocasiones de los rellenos de la mampostería por ejemplo (fig. 4). Este relleno puede emplear material reutilizado, grava y algunos mampuestos de gran tamaño. Sin embargo, cuando estos mampuestos alcanzan una proporción considerable y están dispuestos siguiendo las tongadas, pasará a denominarse tapial calicastrado de cal y cantos.

\section{Tapia real:}

Se dan en el una alternancia de capas de cal y tierra de grosor más o menos igual aunque la parte inferior y superior del cajón la forman una tongada más gruesa de cal.

El problema de las técnicas constructivas son los escasos estudios realizados hasta el momento que pudieran arrojar datos más concretos, sobre todo en lo referente a la cronología. Aunque conocemos la utilización del tapial calicastrado en época nazarí6, es bastante probable que su uso comenzara a extenderse en época almohade. Sin embargo no podemos afirmarlo con seguridad dados los pocos datos de que disponemos. En un mismo periodo parecen convivir tapiales diferentes y multitud de variantes locales con las mamposterías en función también de los materiales disponibles. Arqueológicamente disponemos de varias formas de datación: La estratigrafía mural, a la que ya hemos hecho referencia, nos permite establecer, aunque no en todos los casos, cronologías relativas. De su método

6 Antonio MALPICA CUELLO, “Las técnicas...” (supra n. 1), pp. 299-301. 
de trabajo se han ocupado sobre todo R. Parenti y T. Mannoni ${ }^{7}$. También a través del estudio de los materiales reutilizados en la obra, fundamentalmente la cerámica, además de sillares o material de construcción, metal, etc. que nos ofrecen una cronología absoluta post quem. Igualmente, el análisis comparativo de diferentes o iguales técnicas o materiales en distintos edificios de una localidad o región puede ofrecer interesantes resultados. Aunque, como ya hemos visto en el caso del tapial y la mampostería, distintas variantes parecen convivir y pervivir a lo largo del tiempo, el acopio de datos y su elaboración debería ser una fuente de conocimiento en los próximos años. Ya se hizo con de los aparejos de sillería a soga y tizón de época emiral, califal y taifa ${ }^{8}$ y más recientemente con la identificación del programa de fortificación de Muhammad V a mediados del s. XIV9, constituido por mampostería concertada y encintada con verdugadas de lajas con refuerzos de sillería en las esquinas. Por último aunque no menos importante es el estudio comparativo de las plantas y elementos construidos: puertas, torres, barbacanas, aljibes, almenas, etc., aspectos sin duda sobre los que se ha escrito mucho, pero en los que queda bastante por avanzar.

Pero el valor histórico de los castillos no se reduce ni mucho menos a la cronología. Como restos importantes de la cultura material, son susceptibles de producir conocimiento histórico una vez que se interpreten los códigos que los rigen y se los contextualice. En primer lugar, aunque parezca obvio, hay que tener en cuenta que están hechos para durar y que "están adaptados a la función que tienen que desarrollar y para lo que fueron

7 Roberto PARENTI, "Le tecniche..." (supra n.3) y del mismo: "Sulle posibilità di datazione delle murature", en Riccardo FRANCOVICH, y Roberto PARENTI (eds.), Archeologia e restauro dei monumenti, Florencia, 1988, pp. 280-304 y Tiziano MANNONI, "Metodi di datazione dell'edilizia storica", Archeologia medievale, XI (1984), pp. 396-403.

8 Leopoldo TORRES BALBÁS, "El alminar de la iglesia de S. José y las construcciones de los ziríes granadinos”, al-Andalus, VI (1941), pp. 422-446 y Antonio MALPICA CUELLO, "Las técnicas..." (supra n.1), pp. 318-324.

9 Leopoldo TORRES BALBÁS, “Arte almohade. Arte nazarí. Arte mudéjar”, en Ars Hispaniae, vol. IV, Madrid, 1951; Manuel ACIÉN ALMANSA, "Los tugur del reino nazarí. Ensayo de identificación", Castrum, 5, Murcia, 1999, pp.427-431; del mismo, "La fortificación en al-Andalus", en Rafael LÓPEZ GUZMÁN (ed.), La arquitectura del Islam occidental, Barcelona, 1995, pp. 29-41, pp. 40-41; Antonio MALPICA CUELLO, "Las técnicas..." (supra n.1) pp. 332-333 y del mismo, "Los castillos en época nazarí. Una primera aproximación”, en Antonio MALPICA CUELLO (ed.), Castillos y territorio en al-Andalus, Granada, 1997, pp. 246-293, pp. 270-272. 
creados"10. En segundo lugar, los objetos son producto y reflejo de la sociedad que los creó. Como tales son parte de su cultura material y no pueden comprenderse fuera de su contexto que sobrepasa los aspectos meramente técnicos. Ya se ha aducido en varias ocasiones la facilidad de realizar el tapial y la menor inversión en trabajo, tiempo y recursos frente a la construcción en sillería ${ }^{11}$. Sin embargo, eso no es suficiente. Antes bien hay que explicar por qué se deja de utilizar la sillería con el aparejo a soga y tizón en la época taifa; por qué convive esta con obras estatales califales de tapial como Baños de la Encina (Jaén) o las defensas de la ciudad de Badajoz y por qué mientras en Aragón se construye Loarre y en Castilla las murallas de Ávila con piedra, en al-Andalus parece optarse claramente por el tapial. Es verdad que la mampostería no requiere una mayor especialización ni mayores recursos que el tapial, siempre y cuando los materiales se encuentren in situ. También es cierto que, a pesar de la pobreza de sus materiales, la Alhambra de mediados del siglo XIV no es comparable a prácticamente ningún edificio de la época en los reinos cristianos. Es más, la arquitectura andalusí sigue siendo un referente que se puede ver claramente en los alcázares de Sevilla construidos por Pedro I. Tal vez las únicas edificaciones parangonables sean las grandes obras religiosas del momento, fundamentalmente las catedrales, hecho lo suficientemente significativo de las radicales diferencias entre ambas formaciones sociales.

El Marquesado del Zenete se sitúa en la cara Norte de Sierra Nevada y se extiende desde sus cumbres, al Sur, hasta las de la Sierra de Baza, al Norte, quedando en medio de ambas el amplio valle del Zalabí. Al Este limita con la provincia de Almería y, al Oeste, con la Hoya de Guadix.

Al observar su paisaje lo primero que llama nuestra atención es la brusquedad del contacto entre las montañas de Sierra Nevada en el Sur y la penillanura, ligeramente inclinada, formando el valle. Pero más allá de esa primera impresión, creada por los contrastes de volúmenes, se percibe rápidamente la existencia de un tercer dominio topográfico a lo largo de la

10 Antonio MALPICA CUELLO, “Las técnicas...” (supra n. 1), p. 286.

11 Rafael AZUAR RUIZ, "Las técnicas constructivas en al-Andalus. El origen de la sillería y el hormigón de tapial”, en V Semana de Estudios Medievales de Nájera, Logroño, 1995, pp. 125-142, p. 135 y Antonio MALPICA CUELLO, "Las técnicas..." (supra n. 1), p. 309-310. 
línea de contacto entre el llano y el piedemonte. Se trata de una banda estrecha con dirección Este-Oeste, de apenas un kilómetro de ancho, aunque sensiblemente irregular en su trazado, sobre la que se concentran los paisajes más humanizados. Hacia el Norte, a unos 1000-1200 m de altitud, se produce la transición con el altiplano, sin tanta brusquedad por la presencia de los cultivos que se prolongan a lo largo del valle. Aquí, una serie de cerros desprendidos de la masa principal de la sierra jalonan el paisaje condicionando la ubicación de los últimos pueblos y las características del parcelario. Hacia el Sur, la franja se dilata a intervalos para penetrar en la montaña, buscando los fondos de valle que bajan desde la Sierra perpendicularmente al eje Este-Oeste trazado por sus cumbres y el pasillo del Zalabí. Aquí es donde se localizan los ocho pueblos que conforman el Zenete y sus respectivas vegas ${ }^{12}$.

Los términos municipales se organizan perpendicularmente a esta orientación, en estrechas franjas que se extienden de Norte a Sur ocupando prácticamente toda la longitud posible entre las cumbres de Sierra Nevada y las de Baza. Las únicas excepciones son las de Alquife y La Calahorra, que cubren esencialmente una fracción del altiplano y no poseen apenas montaña al Sur. A esto debemos añadir la reciente creación del municipio del Valle del Zalabí que incluye a Charches en la falda de la Sierra de Baza, antigua aldea de La Calahorra y que rompe parte de este esquema, pero del que no nos ocuparemos en esta ocasión.

De los elementos antrópicos del paisaje dos son los que más destacan: las extensas vegas que llevan los regadíos desde los fondos de valle hasta bien entrado el altiplano y la minería, especialmente destacable en el caso de Alquife, cuyas escombreras son visibles desde toda la comarca. La extensión del regadío es posible, no sólo por la existencia de unos recursos hídricos abundantes procedentes de las nieves de Sierra Nevada, que cumple una función de "pantano natural", sino también gracias al control y organización de esos recursos en una extensa red de infraestructuras hidráulicas compuesta por numerosas acequias, balsas y aljibes ${ }^{13}$.

12 André HUMBERT, "Le Marquesado del Zenete, signification géographique d'une comarca", en Sierra Nevada y su entorno. Actas del encuentro hispano-francés sobre Sierra Nevada, Granada, 1988, pp. 9-29, p.12.

13 José Ma MARTÍN CIVANTOS, "Transformaciones del paisaje en el Zenete (Granada): la creación de las vegas", en Primeras Jornadas de Historia Rural y Medio Ambiente en la Andalucía Medieval (Almonte, 23-25 de Mayo del 2000). Huelva, 2003; del mismo: Poblamiento medieval y organización del territorio en el Zenete (Granada), en prensa.

192 
En total hemos documentado hasta veintiuna estructuras fortificadas, incluyendo el castillo-palacio renacentista de La Calahorra (sobre el que no hablaremos), las torres de Jérez del Marquesado y las atalayas de Huéneja y el Cerro de Juan Canal. Todo ello hace del Zenete, sin duda, una comarca singular. Hacer ahora una descripción de las fortificaciones sería, a pesar del indudable interés, demasiado extenso, por ello deberemos centrarnos en aquellos aspectos más relevantes de las técnicas y los tipos constructivos encontrados hasta el momento ${ }^{14}$.

La mampostería está presente en todas las edificaciones, en algunas sólo como base de los tapiales, pero en la mayoría como obra con entidad propia en una o varias de las fases constructivas. En los yacimientos altomedievales de Alrután en Jérez, Castillo de la Reina de Lanteira, el Castillejo y el Cardal en Ferreira y Zamarriche en Dólar encontramos una mampostería no concertada de lajas - excepto en el Cardal ya dentro del dominio de los mármoles nevado-filábrides-, tomada con tierra o simplemente a hueso. Las construcciones no son, por lo general, de una gran entidad, salvo en el Castillo de la Reina reocupado entre los siglos XII y XIII y Alrután y el Cardal, que son en realidad asentamientos antiguos reutilizados en los que la obra medieval tiene mucha menor presencia. Se suelen adaptar al terreno, normalmente escarpado, que hace las veces de defensa natural. En muchos casos incluso, la mampostería se limita a rellenar el espacio entre los afloramientos rocosos o a servir de parapeto para evitar la caída en los riscos.

La mampostería aparece también en las torres atalayas de todo el Reino de Granada. En el Zenete había como mínimo dos: una en el Cerro de Juan Canal (Ferreira), de la que sólo quedan restos de su derrumbe y un pequeño aljibe en la ladera, cercano a ella. Otra en Huéneja, sobre la rambla del Gobernador, en el lugar llamado La Torrecilla y de la que, igualmente, sólo queda un gran montón de escombros. Función de atalaya, aunque no únicamente, tenían las tres torres situadas en torno al castillo de Jérez del Marquesado, en los bordes del barranco del pueblo. La fortificación se encuentra en un meandro del río a una altura menor, por lo que se hace

14 Para una descripción de las mismas consultar José Ma MARTÍN CIVANTOS, Poblamiento medieval... (supra n. 13); Mariano MARTÍN GARCÍA, Jesús BLEDA PORTERO y José Ma MARTÍN CIVANTOS, Inventario de arquitectura militar de la provincia de Granada (siglos VIII-XV) Granada, 2000 y Antonio MALPICA CUELLO, Poblamiento y castillos en Granada, Barcelona, 1996. 
necesaria la presencia de estas tres estructuras. Todas son de planta cuadrangular y están construidas con mampostería encintada con verdugadas de lajas y refuerzo de sillarejo en las esquinas. La que hay en el pueblo es más pequeña $(3,8 \mathrm{~m}$ por $3,65 \mathrm{~m})$ y de desarrollo troncopiramidal. Dada la estrechez del hueco interior seguramente sólo dispondría de una escalera de caracol para acceder a la terraza. También por sus reducidas dimensiones no cabe descartar la posibilidad como se ha sugerido de que se trate en realidad del alminar de la antigua mezquita15 (fig. 5).

La de Alcázar situada al NE del castillo, al otro lado del barranco, es mucho mayor. Tiene planta rectangular de $7,40 \mathrm{~m}$ por $6,90 \mathrm{~m}$ y orientación NE-SO. En la base hay una zarpa de $25-30 \mathrm{~cm}$. Conserva restos del enfoscado en algunas partes y $12 \mathrm{~m}$ de altura de los cuales los cinco primeros guardan la forma prismática, mientras que los siete superiores están ataluzados. La puerta de acceso está a $3 \mathrm{~m}$ de altura, mirando hacia el castillo. Desde ella se accede a una habitación con muros de 1,20 m de grosor, planta de 5 por 4,60 m y altura de 2,60 m. El interior se divide en tres espacios: el primero es un zaguán transversal a la entrada de $2 \mathrm{~m}$ de ancho. En él se sitúa, a la izquierda, la escalera de subida a las otras dos plantas de la que se conservan restos de ladrillos y la impronta del arranque de sus bóvedas. Los otros dos espacios son dos pequeñas salas paralelas de 3 por 1,85 m y orientación NO-SE, separadas por un muro de $90 \mathrm{~cm}$ y cubiertas por bóvedas de mampostería de lajas. En las paredes hay dos troneras: una al SO y otra al NE. De las otras dos alturas, por el estado de la construcción, no es posible tomar medidas. Los muros perimetrales se hacen algo más delgados, apenas un metro de ancho y las dos plantas tenían saeteras: la segunda dos al NE, dos al SO y una al SE y la tercera dos al NE y una al SO. Ambas plantas se cubrían también con bóvedas de mampostería de lajas de las que quedan restos. No se conserva nada de la terraza superior, ni tampoco del posible aljibe que pudiera haber en la parte inferior al igual que en otras torres de similares características en diferentes lugares (fig. 5).

La tercera de las torres es el llamado Torreón, situado también al E. del barranco, pero al SE de la fortaleza. Es la peor conservada de todas, seguramente de planta rectangular y desarrollo prismático, aunque el único

15 André BAZZANA, Patrice CRESSIER y Pierre GUICHARD, Les châteaux ruraux d'alAndalus. Histoire et archéologie des ceu§œn du Sud-Est de l'Espagne, Madrid, 1988, p. 16. 
lado que conserva completo es el $\mathrm{N}$, con 5,75 m de longitud. Se levanta sobre una zarpa y está construida con mampostería encintada con verdugadas de lajas y esquinas reforzadas con sillarejo. Conserva restos de enfoscado y una altura máxima de $4 \mathrm{~m}$. Por sus dimensiones es posible que también fuera habitable o que sirviera de refugio al igual que la cercana de Alcázar y por su construcción debería fecharse también a partir de mediados del s. XIV (fig. 5).

El cerro del castillo de Jérez (fig. 5) tiene forma triangular y, desde su base al $\mathrm{E}$, junto al río, hasta el vértice al $\mathrm{O}$, en la parte más alta y escarpada, se extiende la fortaleza, organizada en varios recintos y abancalando el terreno a diferentes alturas. En total son seis las terrazas que pueden distinguirse, aunque no todas corresponden a recintos amurallados. Además, el deterioro, pero sobre todo el uso continuado como terreno de cultivo hasta hace pocos años, han causado transformaciones, especialmente en las paratas, cuyo alcance no nos es posible determinar hasta el momento, pero que en algunos casos hace imposible el reconocimiento de las estructuras antiguas.

El recinto más alto tiene forma triangular. En dos de sus lados la escarpada roca actúa de defensa natural, a pesar de lo cual hay una importante muralla en todo su perímetro de la que sólo el lado $\mathrm{E}$, la base del triángulo, es de mampostería. La torre de la esquina SE (T3) es de mampostería de lajas apenas concertada, de una factura muy parecida a las obras de mampostería de Alquife, aunque en su interior y en la parte $\mathrm{O}$ parece tener algún resto de una torre anterior de tapial. Es cuadrada y alcanza aproximadamente los $5 \mathrm{~m}$ de altura. La parte mejor conservada es la esquina NE donde quedan aún restos del enfoscado con un llagueado en vitolas de pequeño tamaño que apenas dejan ver los mampuestos. En el lateral $\mathrm{N}$ puede apreciarse cómo el relleno y algunos mampuestos sobresalen de la línea de muro, en parte por simple desprendimiento. El enfoscado tiene, además, un corte de arriba a abajo con rebabas, como si hubiera habido alguna estructura adosada, en este caso trabada con la torre. Sin embargo, no podemos asegurarlo con certeza plena.

En el mismo frente se le adosa una casa de una sola planta sobre cuyo techo cae parte del relleno de la torre. La vivienda ocupa el espacio de la muralla E (M3) entre la torre descrita y la siguiente hacia el N (T4), apenas visible. El paño de muralla queda en parte conservado por su reutilización como muro. Aprovecha la roca, esta vez cortada a plomo hasta una altura de $1,65 \mathrm{~m}$, y sobre ella se conservan otros $2,30 \mathrm{~m}$ de mampostería apenas concertada. La longitud total del paño es de $6,30 \mathrm{~m}$. En la esquina $\mathrm{N}$, la 
mampostería rellena una grieta de la roca y la torre (T4), aprovecha también parte de la roca trabajada sobre la que se asienta la mampostería, en el interior de la casa apenas reconocible como antigua, pero en el exterior sí que hay un relleno importante y una línea de varios mampuestos que delatan la presencia de la torre.

Más hacia el $\mathrm{N}$, continuando en la base del triángulo, la muralla se pierde por completo y sólo vuelve a aparecer en la esquina NE el relleno de una torre (T5), aunque no es posible discernir si se trata de una mampostería o de tapial calicastrado de cal y cantos ya que, tanto por su composición como por su disposición, ambos son prácticamente idénticos una vez perdida la capa exterior. El triángulo se cerraría con el lateral $\mathrm{N}$, que se dirige hacia el $\mathrm{O}$ hasta alcanzar de nuevo el vértice, discurriendo por una escarpada roca en la que no pueden verse restos de amurallamiento.

En el siguiente nivel hacia abajo es una terraza cerrada por una nueva muralla. En el S se une a la torre de mampostería (T3) con una muralla de tapial (M4) que se vuelve hacia el NO formando otra nueva torre (T6) de calicastrado de cal y cantos. Su estructura y la de la muralla adosada a ésta hacia el E (M5) es difícil de reconocer debido a las transformaciones y derrumbes posteriores. Formando la torre (T6), en dirección N-S, hay dos muros de tapial paralelos cuyo espacio intermedio está en parte relleno. Podría tratarse de una torre con habitación. La muralla que arranca hacia el E (M5), tiene hasta cuatro líneas de muro paralelas: dos de mampostería más elevadas en el interior (una de ellas muy fragmentada), de las que alguna debe corresponder a una reparación de la parata; una intermedia de tapial calicastrado que sólo conserva cara hacia el interior y, por último, la más exterior y más baja, también de mampostería, que parece ser una reparación de la de anterior de tapial y que tiene en su parte baja una atarjea para desagüe. Todas ellas están adosadas al muro de tapial de la torre (T6). En la esquina SE al final de la muralla, hay restos de la cimentación de una torre de mampostería. A partir de aquí, la muralla gira hacia el N. Está toda construida en mampostería y en la parte central hay una torre (T7) rectangular de 4,20 por $1,60 \mathrm{~m}$ por $2 \mathrm{~m}$ de alto.

En la parte baja de la esquina NE de la muralla, ya en la siguiente terraza, aparece uno de los elementos más interesantes de toda la fortificación: se trata de una canalización de mortero de cal, en parte excavada también en la roca que discurre junto al camino de acceso realizado en mampostería rodeando todo el peñón desde el $\mathrm{O}$, salvando incluso dos desniveles mediante 
muros de mampostería. Sobre la entrada de la acequia al castillo hay un pequeño puente y unas escaleras de mampostería que llevan al bancal superior. Es aquí, un poco antes de esa entrada, donde debía estar situada la puerta de acceso, en un paño de muralla que debería ir desde la torre NE (T5) del primer recinto hasta una situada en la zona inferior (T8), sobre una roca de la que apenas son visibles unas hileras de mampuestos.

Desde este punto hasta el río son visibles algunos restos más en el perímetro del recinto. Todos ellos en mampostería sobre la roca, en algunos casos reutilizados o reformados por las paratas para el cultivo. Tan sólo aparece de nuevo un pequeño resto de tapial calicastrado en el lado $S$ otra vez forrado por una mampostería. Aquí hay hasta cuatro terrazas más sujetas por muros irregulares de mampostería a piedra seca. En la más baja de estas terrazas hay un gran agujero en el suelo, seguramente un pozo que captaba la capa freática del cercano río a modo de coracha.

De mampostería de lajas es también buena parte de la obra del castillo de Aldeire, el más grande e impresionante de todos los del Zenete. Donde más destaca es en el gran bastión semicircular del extremo E (T1. Figs. 6 y 7) ${ }^{16}$, con un perímetro de unos $11,80 \mathrm{~m}$, unos $5,60 \mathrm{~m}$ de grosor máximo y 7,30 m de altura. Cimentado directamente sobre la roca, no sobresale de la línea de muralla que se dirige hacia el O (M1), aunque sí es unos dos metros más alto que esta. El paño sigue en línea recta unos $11,30 \mathrm{~m}$ y tiene un grosor máximo de 2,30. Ambas estructuras son de mampostería concertada en hiladas, pero no encintadas. Están enfoscadas con un llagueado en vitolas que deja ver parte de los mampuestos y en la parte superior de la torre y la muralla hay partes con un revestimiento total, posiblemente una reparación posterior. Hacia el interior se encuentra un aljibe pequeño, embutido entre el bastión y las murallas que a ambos lados se dirigen hacia el $\mathrm{O}$, ocupando todo el espacio posible y adosándose a las estructuras. Es, por tanto, posterior a ellas, aunque seguramente de la misma época. En la parte alta del bastión y de la muralla descrita son apenas visibles restos de tapial calicastrado: se trata de merlones de $0,50 \mathrm{~m}$ de ancho por $1 \mathrm{~m}$ de longitud aproximadamente. Es posible que sean contemporáneos ya que no es extraña la asociación entre las murallas de

16 Los códigos junto a los elementos descritos indican el número de estructura. Para una descripción más completa véase José Ma MARTÍN CIVANTOS, "El castillo de La Caba en Aldeire (Granada)", en Actas del III Congreso de Historia de Andalucía, Córdoba 2001, Andalucía Medieval II. Córdoba, 2003, pp. 433-457. 
mampostería y el almenado de tapial como puede verse en el castillo de Moclín (Granada).

De mampostería de lajas son también gran parte de las estructuras que, a partir de aquí, forman el perímetro amurallado. En este caso no es concertada, aunque las lajas le dan un aspecto ordenado. Podría por tanto, en principio, distinguirse de la anteriormente descrita. Sobre ella se apoya una obra en tapial de tierra no siempre conservada. Sin embargo, la mampostería parece no reducirse a ser solamente la cimentación y basamento del tapial como en la mayoría de las ocasiones, ya que se han llegado a medir alturas de más de dos metros, a las que habría que añadir la parte oculta bajo el relleno. Se trataría, pues, de una obra mixta en la que se asocian ambas técnicas a un mismo tiempo. En la cara S, como hemos dicho, la muralla se adapta a la roca, rellenando grietas y aprovechándola como elemento defensivo en el borde mismo de los riscos. Aquí también encontramos una obra mixta (T12), pero no de tapial de tierra, sino calicastrado de cal y cantos. Los mampuestos se unen con escaso y pobre mortero y se cubrían con un enfoscado de cal de 2 a $8 \mathrm{~cm}$ de grosor visible en una de las torres del lado N (T8) y en parte en la torre del frente S (T12). Hasta donde hemos podido observar, al menos en la primera, el revestimiento es total, y no dejaría ver los mampuestos de la parte interior. Por último, de mampostería son también los escasos restos que afloran de la barbacana en la ladera $\mathrm{N}$ a unos dos metros de distancia de las torres de ese flanco.

En el castillo de Alquife (fig. 8) ${ }^{17}$ puede verse con claridad cómo la torre NO ha sido reparada mediante un forro de mampostería que cubre el relleno del tapial calicastrado anterior solo en el lado Oeste. No debe de tratarse de una reforma intencionada, ya que solo afecta a uno de sus cuatro lados y no es un simple forro sobre la cara del tapial igual que ocurre en otros castillos del reino Nazarí de Granada, sino que la torre ha sido cortada irregularmente y sobre ella se adosa un nuevo mortero más claro, más rico y resistente que el relleno del calicastrado y de mampuestos más grandes. Sobre este está el muro de mampostería, más alto que la base del mismo material para el tapial. La obra presenta, además, una curiosa decoración en el rejuntado de las piedras con incisiones verticales y paralelas en el mortero y

17 José Ma MARTÍN CIVANTOS, “Alquife, un castillo con vocación minera en el Zenete (Granada)", Arqueología y Territorio Medieval, 8 (2000), pp. 325-345. 
fragmentos de mineral embutidos. Esta forma decorativa distingue además esta obra de la base de mampostería del tapial perfectamente conservada en la torre SO por ejemplo.

La siguiente torre hacia el Este (TN1) es obra de mampostería en su totalidad. Conserva casi completas las fachadas $\mathrm{O}$ y $\mathrm{N}$ y una considerable altura. Está macizada por un relleno relativamente pobre en cal. En su cara S, la que da al interior del recinto, es posible apreciar la unión con la muralla que hacia el $\mathrm{O}$ es de tapial calicastrado y hacia el $\mathrm{E}$ de cal y canto. Aunque difícilmente, se observa una esquina de un cajón del tapial calicastrado a ras del suelo sobre el que se apoya el relleno de la torre que es, por lo tanto, claramente posterior. A este relleno se le apoya, a su vez, un muro de 0,5 m de ancho por $2 \mathrm{~m}$ de largo que sale de la misma cara $\mathrm{S}$ en dirección S-SE, hacia el punto geodésico. Es también de mampostería, sin llagueado y con el mismo relleno. Cabe no obstante señalar un aspecto aún más interesante de esta torre: también presenta la decoración con mineral de hierro y escorias anteriormente descrita, pero sólo en la zona inferior izquierda de la fachada $\mathrm{N}$ y no en el resto a pesar de conservarse buena parte del rejuntado de los mampuestos. Pudiera tratarse pues, de una nueva reparación aunque no sabemos si anterior o posterior. En esta misma zona, algo más abajo, se puede apreciar claramente la esquina de la fachada rehundida y rejuntada. No parece que pueda ser fruto de un error constructivo, ni de un deslizamiento del terreno, sino más bien de una nueva reparación. A nuestro juicio, la parte baja podría ser un resto de la base de mampostería de una torre anterior de tapial igual a la del $\mathrm{NO}$, que, tras ser totalmente destruida, fue rehecha en mampostería. Por último, aún más hacia el E encontramos otra torre. Son sólo algunos mampuestos en línea y parte de un relleno de mortero que no nos permiten decir si estamos ante otra torre de mampostería o la base del mismo material de una de tapial.

El Fuerte de Lanteira esta situado dentro del núcleo urbano, en la calle del Fuerte. Es una torre de importantes proporciones, seguramente dentro de un recinto amurallado, una albacara del que podrían quedar restos en las paratas de la ladera que baja al río del Pueblo. La planta es ligeramente rectangular, de $14,40 \mathrm{~m}$ por $14,10 \mathrm{~m}$ con dirección en el lado mayor E-O. Tiene una altura máxima de $6,50 \mathrm{~m}$ correspondientes a dos plantas en el interior. De estas, la baja está construida en mampostería concertada de lajas en la parte inferior y las esquinas y de cantos en la zona superior. Los muros tienen 1,55 m de grosor excepto en el lateral E que sólo tiene 1,15 m. La parte 
alta está realizada con tapial de tierra pobre en cal y $1,15 \mathrm{~m}$ de espesor, conservando hasta una altura de tres cajones en el lado $\mathrm{N}$.

Aunque actualmente presenta numerosos vanos de ventanas y puertas, es posible que la original sea un hueco cegado en la fachada S, situado a la altura de la primera planta. En el interior, la planta baja tiene un espacio de 11,70 por $11 \mathrm{~m}$. La puerta actual de entrada y la escalera están en el ángulo SE, y el resto está compartimentado por muros de carga de mampostería de 40-50 $\mathrm{cm}$ de espesor, formando naves laterales que dejan un espacio rectangular en el centro. El techo se cubre con un forjado de rollizos de madera y tablazón y la planta alta está dividida con tabiquería moderna. La esquina NO tiene el suelo roto y puede verse el arranque de una bóveda de ladrillo, tal vez el resto de un aljibe reutilizado posteriormente como horno. Los suelos son de tierra y actualmente se encuentra cubierto por una techumbre plana de lajas.

De similares características podría ser la Fortaleza de Aldeire, situada dentro de la población en la calle de las Torres y de la que solo se observan gruesos muros de mampostería claramente visibles en algunos de los edificios de la manzana rehabilitados recientemente.

De tapial de tierra, no demasiado rico en cal, es la mayoría de la obra que, como acabamos de ver, se encuentra sobre la mampostería en el castillo de Aldeire (fig. 6). En él hay bastantes mampuestos de mediano y gran tamaño, aunque lo suficientemente desordenados y escasos como para no poder hablar de un tapial de cal y cantos. También hay cerámica, entre las que hemos hallado algunos fragmentos de ataifores melados con trazos de manganeso y de una jarrita pintada con bandas blancas, todas, en principio, del siglo XI (M2). En general se encuentra bastante deteriorado y se ha perdido en bastantes sitios (en todo el frente S, por ejemplo, no aparece), aunque su presencia fragmentaria pero repetida, nos lleva a pensar que sería la técnica constructiva (mixta de mampostería y tapial), que formaría una primera época del castillo hoy visible. Se aprecia de forma inequívoca en todo el paño $\mathrm{N}$, bajo las reformas posteriores que más adelante veremos. Aquí habría hasta ocho torres rectangulares algunas hoy irreconocibles, todas seguramente transformadas a lo largo del tiempo. Las medidas de dos de las torres más completas (T8 y T9) coinciden: 2,30 m de ancho por 3,50 de largo, aunque no las de una de las más orientales que solo conserva completo el lado E con $2 \mathrm{~m}$ de longitud (T5). Las torres se traban a la muralla en la parte baja, la de mampostería, pero el tapial solo se apoya y tiene, además, en el inicio 
del cajón que se adosa al muro, una columna de mampuestos (T5).

De tapial hormigonado son todos los aljibes encontrados excepto el de Alrután, en realidad una cisterna romana excavada en la roca y reaprovechada. El del castillo de Jérez, el de la Reina de Lanteira, Alquife, los dos de Aldeire, el de Ferreira y Dólar están construidos con este material hasta el arranque de la bóveda que generalmente es de mampostería de lajas. Todos están bien defendidos en el centro de las fortificaciones o protegidos por la muralla, pero nunca expuestos a un posible ataque. Excepto el grande de Aldeire, con tres naves unidas por un arco de medio punto y de planta ligeramente trapezoidal, y el de Jérez, de pequeñas dimensiones y también en forma de trapecio, el resto son de una sola nave rectangular. Suelen estar semienterrados o semiexcavados en la roca y aprovechan el agua de lluvia recogida para abastecerse. El único ejemplo de canalización de aguas es el descrito en el castillo de Jérez, que introduce una acequia a la altura de la tercera terraza salvando un desnivel, pero que se pierde al entrar en el recinto y no quedan huellas de un segundo aljibe. El interior se enluce con mortero de cal y en algún caso, como en Dólar, hay molduras de media caña en las esquinas para reforzarlas. En este último castillo además, la estructura está construida sobre otra anterior a la que rompe, visible en parte en el lado O. Se trata de otro aljibe, del que se conserva parte de uno de los muros cortos de 2,33 m de largo con el enlucido y el arranque de la bóveda de mampostería de lajas. Al E hay otro muro adosado de tapial de hormigón, aunque no nos ha sido posible determinar con certeza cual es anterior. Seguramente es un paño de muralla posterior ya que envuelve parte del aljibe más moderno. Tiene en total 7,50 m de longitud y una altura máxima de 1,80 m. El grosor varía desde $1,50 \mathrm{~m}$ en el contacto con el aljibe a los $2,50 \mathrm{~m}$ al S. Al $\mathrm{N}$ se estrecha y se bifurca, dibujando una esquina que hace que el muro siga hacia el $\mathrm{O}$ envolviendo al aljibe y hacia el $\mathrm{N}$ en dirección al reciente depósito de agua que ha destruido parcialmente el castillo.

Al resto del aljibe más antiguo se le adosa un muro de tapial calicastrado con una longitud conservada de 4,20 m y una altura máxima de $95 \mathrm{~cm}$. Se puede ver algo del enlucido, pero está tapado por otra estructura que ocupa gran parte del lado $\mathrm{O}$ y que se le adosa posteriormente. Se trata de una habitación de planta pentagonal irregular (fig. 9), más ancha en el lado $\mathrm{N}$ $(1,70 \mathrm{~m})$, que en el $\mathrm{S}(1,35 \mathrm{~m})$ y con una longitud total de 7,45 $\mathrm{m}$ en el interior. El grueso de los muros también varía: parte del lateral E, en el contacto con el paño de tapial calicastrado al que acabamos de referirnos, sólo tiene $40 \mathrm{~cm}$, 
mientras que en el resto alcanza los $90 \mathrm{~cm}$, es decir, aprovecha el muro de la fase anterior. Tiene una altura máxima conservada de 2,60 m. La estructura apoya sobre la roca y aparentemente sólo tiene algunos mampuestos para nivelar. El suelo de la habitación es de mortero de cal y mampuestos que rellenan y nivelan el terreno. Los dos primeros cajones son de tapial de cal y cantos, aunque con mampuestos medianos y relativamente desordenados que lo asemejan al hormigón. Los dos cajones superiores conservados son de tapial hormigonado. En el interior conserva algo del enlucido. Todo este conjunto parece dibujar un primer recinto más pequeño en la parte superior del cerro. Más abajo, en la ladera, hay restos de un segundo, algo más grande que, al igual que el primero, tenía planta cuadrangular con dirección N-S. De éste segundo quedan fragmentos de tres torres en las esquinas NO, SO y SE. La primera, la mejor conservada, tiene 4,20 por $3,30 \mathrm{~m}$ y una altura de unos $3 \mathrm{~m}$. Las otras dos no pueden medirse. Las tres son obra de tapial calicastrado sobre una base muy pequeña de mampostería y entre ellas aún puede intuirse algún resto de la muralla que las unía.

Al S del conjunto, en un nivel más bajo hay una alberca rectangular de 7,80 por $3,30 \mathrm{~m}$, con orientación E-O y construida con muros de hormigón de $48 \mathrm{~cm}$. Esta semienterrada y el lateral $\mathrm{E}$ ha desaparecido. Su función fuera del recinto amurallado nos es desconocida y, aunque parece estar asociada a la fortificación es también probable que sea posterior. En cualquier caso no hay restos de ningún tipo de conducción de agua, ni por su elevación parece posible hacerlo sin una obra de gran porte, por lo que debería llenarse con agua de lluvia recogida de la parte superior, es decir, del castillo. Es además en la ladera del cerro, donde estaría situada la alquería, sin ocupar la vega, siguiendo el modelo ya trazado y que tan claramente se ve en el caso de Ferreira. Es por tanto posible que la alberca estuviera destinada al abastecimiento de la población, aunque tampoco tendría mucho sentido si, como sucede en algunos de los otros pueblos de la comarca, las acequias proporcionan también agua a los aljibes públicos.

En La Calahorra, los restos de muros y torres conservados después del desmantelamiento de la fortaleza por parte del primer marqués del Zenete para la construcción del nuevo edificio renacentista, se concentran en la zona $\mathrm{O}$ y N. En el lateral Occidental quedan restos de seis estructuras cuadrangulares y de una muralla que une tres de ellas. Todas ellas están realizadas en duro hormigón. En el extremo $\mathrm{N}$ se observan los restos de una torre, por sus dimensiones $(9,35 \mathrm{~m}$ en la cara $\mathrm{N}$ por $5,95 \mathrm{~m}$ conservados en la 
E ), seguramente habitable. Está construido en hormigón de gran dureza en su parte baja y, sobre él, todavía quedan los vestigios de un cajón de tapial calicastrado. Probablemente la parte de hormigón corresponda a un aljibe en la parte inferior de la torre. A nuestro juicio se deben distinguir dos fases: La más antigua habría que relacionarla con los restos de estructuras de hormigón que aparecen a lo largo del cerro y podrían pertenecer a un castillo de mayores proporciones que verdaderamente ocupara toda la cima. Sería una fortificación de las denominadas de cremallera, del mismo tipo que la de Aldeire o la primera fase de Alquife pero de mayor tamaño aún. No sabemos si tal vez englobara parte del poblamiento como en el caso de Aldeire. Así parece desprenderse por la gran cantidad de cerámica a lo largo de todo el cerro. Una fase más reciente se corresponde con el gran torreón y los restos de tapial calicastrado. Es posible que correspondan a una estructura parecida a la del Fuerte de Lanteira o la Alcazaba de Ferreira.

El tapial de cal y cantos es especialmente importante en el castillo de Alquife (figs. 3 y 8). En este material están construidas las dos torres orientales y los paños de muralla que las unen entre sí y con la siguiente torre al NO, justo al N del punto geodésico. Igualmente son de cal y cantos el lienzo entre esta última torre y la siguiente hacia el $\mathrm{O}$ de mampostería y, al $\mathrm{S}$, el que hay al E de la torre del ángulo SO. Por último también encontramos, como continuación más oriental del anterior, un pequeño trozo bajo el resto de una torre de tapial calicastrado situada justo al $\mathrm{S}$ del punto geodésico, prácticamente destruida por los derrumbes de una de las explotaciones mineras. Es un tapial muy rico en cal con mampuestos de mediano tamaño de caliza tomados del propio terreno. Aquí, las agujas están sujetas al cajón inferior mediante clavos o cuñas hincadas en el mortero cuyas huellas son visibles en una de las torres. A este mismo clavo se debe amarrar también una cuerda de esparto que sujete los costales y evite que se abran. Es interesante observar como la mayoría de estas estructuras corresponden al lado oriental, mientras que en el occidental se encuentran las reformas posteriores en tapial calicastrado y en mampostería, cuestión sobre la que volveremos más adelante.

El castillo de Huéneja se encuentra en el llamado barrio del Castillo, dentro de la localidad, sobre una pequeña elevación al $\mathrm{S}$ de la iglesia en el margen derecho del río Izfalada. Son muy escasos y fragmentarios los restos, visibles sobre todo en el frente $\mathrm{O}$, donde quedan restos de torres en los ángulos $\mathrm{NO}$ y $\mathrm{SE}$, así como algunos trozos de muralla entre las casas del 
barrio. La obra es de tapial de cal y cantos, utilizando para ello no lajas de esquisto como es lo habitual en las casas del pueblo sino cantos rodados de caliza normalmente. En la esquina NO aparecen dos líneas de muralla distintas a diferente nivel: la superior, más gruesa y de mayor potencia, con dirección NE-SO y la inferior, más hacia fuera, con dirección N-S. La presencia de casas nos ha impedido hacer un análisis más detallado, pero la primera estructura debe corresponderse con una torre en la esquina $\mathrm{NO}$ y la segunda con un resto de muralla, pero no podemos determinar por qué están a dos alturas y en dos líneas diferentes. La de la esquina SE es aún de mayor entidad. Se encuentra entre las casas, como cimiento de una de ellas de hecho, y es solo visible desde la ladera de enfrente. El paño debe de tener alrededor de $7 \mathrm{~m}$ de largo por unos 3 de alto. Conserva algo más de tres cajones sobre una pequeña base de mampostería y la cara exterior de dos de ellos en los que se aprecian los agujeros de las agujas del encofrado. Al parecer, también se conserva el aljibe en el interior de una de las viviendas a la que no hemos tenido acceso. Así lo recoge también P. Madoz en su diccionario: "El barrio del Castillo está en el centro; en su parte superior hay vestigios de una fortaleza de tiempo de moros, que dominaría toda la población, conservándose restos de sus murallas; tiene 300 pasos de diámetro, una plazuela en medio, conocida entre los naturales con el nombre de Turrion, en la que se descubre el borde de un estanque ó cisterna de 3 varas cuadradas, sin que hayan descubierto su profundidad"18. Por lo exiguo de las estructuras se hace muy difícil la interpretación de las mismas. Tenemos noticias de Huéneja (Winya) del siglo IX durante la fitna. Este sería uno de los castillos fieles a los Omeyas, en el que permaneció varios días Hisam, tío del Emir 'Abd alRahman ibn al-Hakam durante la campaña contra Tudmir del año 89619. Sin embargo, los restos que hoy vemos muy posiblemente no tengan nada que ver con aquella primera fortaleza.

En Aldeire (fig. 7), todo el conjunto realizado en mampostería y tapial de tierra se ve reformado en un momento concreto y de forma más o menos homogénea. Las torres descritas en el frente $\mathrm{N}$ se forran en tapial, pero

18 Pascual MADOZ, Diccionario Geográfico-Estadístico-Histórico de España y sus posesiones de ultramar, Madrid, 1845-1850. Ed. facs. Salamanca, 1987, p. 208.

19 IBN HAYYAN, “Al-Muqtabis III", Trad. E. GURAIEB, “Al-Muqtabis de Ibn Hayyan”, Cuadernos de Historia de España, XIII-XXXII (1950-1960), XXVII (1958), p. 165. 
también en su mayor parte con una obra mixta, de cal y cantos en la parte inferior y de calicastrado en la superior.

La reforma de tapial de cal y cantos y calicastrado es visible sobre todo en las torres centrales (T5-T9. Figs. 10 y 11). La primera comenzando por el E(T5) ya la hemos descrito como obra de mampostería y tapial de tierra, pero en la parte inferior son visibles aún restos de mortero adosado a ella aunque no dan cara y están por completo enterrados. La segunda es una torre (T6) rectangular de $3,15 \mathrm{~m}$ por $5,75 \mathrm{~m}$, construida de tapial de cal y cantos hasta los 2,15 $\mathrm{m}$ de altura y a partir de ahí hecha con calicastrado. El cajón del calicastrado no tiene cara hacia el interior ni tiene un relleno, sino que se apoya sobre la estructura que lo rellena, que por tanto es anterior, sin duda el tapial de tierra de una de las torres de las que venimos hablando, cuyas medidas además coinciden. Las agujas miden 4 por $7 \mathrm{~cm}$ y en los dos cajones inferiores hay huellas de dos costales interiores semicirculares. La torre se apoya sobre la muralla de mampostería y tapial que la une con las siguientes. La última de las torres (T7), sin duda en la que mejor se ve la reforma efectuada con el forro sobre la anterior (T8), ya descrita, que sobresale unos $2,20 \mathrm{~m}$ por encima. Es igualmente rectangular y mide $5,70 \mathrm{~m}$ por $3,15 \mathrm{~m}$. De nuevo, la parte inferior es de cal y cantos hasta los $3 \mathrm{~m}$. En la parte baja tiene una zarpa de tapial de $15 \mathrm{~cm}$ de ancho por $67 \mathrm{~cm}$ de altura máxima. Sobre el cal y cantos se eleva el calicastrado al menos otros dos metros y dentro se eleva la torre de mampostería y tapial de tierra a la que forra y en la que todavía se pueden ver restos del enfoscado que la cubría. El cajón mide $80 \mathrm{~cm}$ de alto y las agujas 3 por $6 \mathrm{~cm}$.

En ambas torres, el tapial de cal y cantos tiene, como es lógico, numerosos mampuestos, más concretamente de esquistos, de granulometría parecida a la de las obras de Dólar y Jérez, que seguidamente veremos, pero sin duda de tamaño relativamente reducido en comparación con lo observado en Alquife y el Castillo del Barrio de Lanteira o en la Alcazaba Qadima de Granada. De una factura similar, a falta de un análisis más detallado actualmente en desarrollo, parece ser en el castillo de Piñar (Granada), la primera de sus fases constructivas. Ésta a primera vista emplea igualmente el cal y canto con mampuestos de mediano tamaño en la parte baja, y el calicastrado en la superior.

De tapial calicastrado es, en el mismo castillo, la primera de las torres comenzando por el E es, sin duda, la más compleja (fig. 12). Tiene, al menos, dos fases y una posible tercera y cuarta. La última (T2) es un forro de tapial 
calicastrado en su totalidad sobre una pequeña base de mampostería. Tiene planta rectangular de 3,10 por 5,95 por $3,58 \mathrm{~m}$ y una altura máxima de $8 \mathrm{~m}$. En la parte superior tiene un espacio de habitación de 4,40 por $2 \mathrm{~m}$ y una altura conservada de $1,83 \mathrm{~m}$. Está enlucida al exterior con dos capas superpuestas visibles en el ángulo inferior izquierdo del lado mayor; la primera, la inferior, conserva incisiones estriadas practicadas posiblemente para la sujeción del enlucido final y no como elemento decorativo. El mortero tiene muy poca cerámica y es muy rico en cal. Los cajones tienen $76 \mathrm{~cm}$ de alto aproximadamente y $90 \mathrm{~cm}$ de grosor. Las agujas, de 9 por $4 \mathrm{~cm}$ y unos 50 $\mathrm{cm}$ de largo, se sujetan a las tablas del encofrado mediante cuñas de madera que dejan su impronta en el mortero, bien visible sobre todo en el contacto del suelo de la habitación (hoy perdido, pero que tenía unos $30 \mathrm{~cm}$ de grosor) con la pared. En esta misma pared del interior de la habitación puede verse una roza vertical de $97 \mathrm{~cm}$ de alto, realizada cuando el mortero aún estaba fresco. Además, en el corte del tapial roto en el lado O parece adivinarse la presencia de huellas de cruces de S. Andrés que darían rigidez al encofrado, que en este caso sólo se coloca en la parte exterior del cajón ya que hacia el interior es el muro anterior el que hace las veces de contenedor. Por su estrechez, las cruces podrían ser de cuerda, sujeta en este caso desde los costales hasta el muro. La torre se adosa, en el lado E, a la muralla de mampostería que forma el bastión (T1 y M1). En el contacto con ella, el comienzo de los cajones tiene una columna de mampuestos. En la parte O, se adosa a la muralla de mampostería y tapial de tierra (M2). Es, por tanto, posterior a ambas en su última fase. El problema estaría entonces en intentar determinar cuál de los dos paños es posterior. El hecho de que de los dos lados menores de la torre el más corto sea el oriental, es decir, que la muralla de mampostería (M1) sobresale más hacia afuera, y la cerámica hallada en el mortero de la de mampostería y tapial de tierra (M2) ya mencionada, nos inducen a pensar que la primera de ellas (M1) es posterior a la fase constructiva descrita como la más antigua.

La torre descrita (T2) forra otra también de tapial (T3), aunque no podemos precisar más. Puede verse sólo en su lado occidental, que conserva parte de las agujas embutidas. El lateral visible mide $2 \mathrm{~m}$ por $2,80 \mathrm{~m}$ de alto y la longitud de la torre debe ser igual a la de la habitación de la torre que la forra, es decir, 4,40 m. Encima de esta y debajo del relleno del suelo de la habitación encontramos restos de mampostería de unos $30 \mathrm{~cm}$ de alto con mampuestos tomados por un mortero rico en cal, pero no podemos determinar con certeza plena si podría estar asociado a la reforma de mampostería (T1 y 
M1) y por tanto la torre interior (T3) sería anterior, o si, por el contrario, sería una torre anterior de mampostería y tapial de tierra (la fase más antigua) forrada por la de tapial (T3). En el muro (T3) hemos encontrado un fragmento de jarrita almohade-nazarí que nos lleva a pensar que estamos ante una fase distinta, posterior a la de mampostería y tapial de tierra.

Por su parte, el calicastrado de la obra mixta que hemos visto sobre el cal y canto tiene un mortero más pobre y de tono más grisáceo que el de la primera torre descrita (T2). Además, como ya dijimos, ésta (T2) no emplea la técnica mixta de los dos tapiales, por lo que podría tratarse de una reforma más si admitimos también la posibilidad de que en ella puedan distinguirse tres fases. Sería ésta entonces, teóricamente, la última construcción del castillo. En contra de esta teoría solamente estarían las dimensiones de las otras torres (T6 y T7), muy parecidas a la primera (T2). Deberíamos sin embargo tener en cuenta una nueva técnica utilizada en otra zona de la fortaleza: en la cara S, la única torre identificable (T12) es también de tapial calicastrado pero de cal y cantos sobre una obra también de mampostería de casi $2 \mathrm{~m}$ de alto. Ninguno de los otros dos calicastrados tiene mampuestos en su mortero. Estaríamos, por tanto, en principio, ante otra fase constructiva sobre la que más adelante hablaremos.

En Alquife (fig. 8) de tapial calicastrado es una parte importante de la fortificación. En esta técnica están construidas la torre SO (fig. 4) y la de la esquina NO, la muralla que las une y la que une la última con la torre de mampostería más al E cuyo relleno se apoya sobre el tapial, así como el resto de muralla que parece hacer un quiebro al $\mathrm{S}$ del punto geodésico y que se apoya sobre otro fragmento de cal y cantos. El tapial se construye, como es normal, sobre una base de mampostería que nivela el terreno para comenzar a encofrar y aísla de la humedad. En el lado $\mathrm{O}$ aún son visibles algunos palos de mechinales y tablillas, cuerdas y huellas de las agujas en el encofrado. Dos aspectos llaman la atención sobre las estructuras construidas con esta técnica: una en la muralla $\mathrm{O}$, de la que se conserva un resto de altura considerable entre las dos torres de las esquinas. Aquí se conserva la cara del tapial en el interior pero no en el exterior excepto en el primer cajón de abajo. Sin embargo algunos mampuestos de los cajones superiores sobresalen de la línea de fachada, lo que pudiera indicar que podría haber existido en algún momento una torre intermedia. Al segundo aspecto que llama la atención ya nos hemos referido anteriormente, se trata de la reparación en mampostería de la torre NO, que nos proporciona de manera clara una cronología relativa. 
Por último, en el Zenete va a cobrar una especial importancia el tapial calicastrado de cal y cantos (ya visto en el caso de Aldeire T12), que como sabemos emplea en su mortero un número considerable de mampuestos dispuestos en tongadas, pero que al mismo tiempo tiene la costra de cal en el exterior.

En dos de los lados del triángulo que forma la planta de la parte superior del castillo de Jérez (fig. 5), la escarpada roca actúa de defensa natural, a pesar de lo cual hay una importante muralla en todo su perímetro. En el ángulo $\mathrm{O}$, el vértice del triángulo, hay restos de una torre hueca en su interior (T1). Tiene unos 7,32 $\mathrm{m}$ en el exterior del lado O. El espacio interior es de aproximadamente 4,72 por 2,30 $\mathrm{m}$ y el grosor del muro de 1,30 m. Es obra de tapial calicastrado de cal y cantos que utiliza lajas en el interior. En el lateral SE continúa una muralla del mismo material (M1) prácticamente perdida y adosada a ella el pequeño aljibe de planta trapezoidal ya mencionado. Siguiendo hacia el SE, aparece otra torre (T2), también de tapial calicastrado de cal y cantos, que conserva cara en el lateral S, imposible de medir por su situación. De esta torre parte de nuevo un tramo de muralla hacia el SE del mismo material y que entesta con la torre de mampostería ya descrita de la esquina SE (T3).

Como hemos visto también antes, de tapial calicastrado es, en el siguiente nivel hacia abajo la muralla (M4), que en el lado S se une a la torre de mampostería (T3) y una nueva torre que cierra la terraza en el lado $\mathrm{S}$ junto con la compleja estructura de muros mencionada.

El llamado castillo del Barrio de Lanteira es una pequeña fortificación de planta rectangular y orientación SO-NE situada a las afueras del pueblo actual, al SE, sobre el cementerio. Las medidas exteriores son 33,1 m por 19 $\mathrm{m}$. Es obra de tapial calicastrado de cal y cantos en su totalidad sobre una base de mampostería de lajas. Es una obra homogénea, sin añadidos ni reestructuraciones o fases posteriores a la de su fundación. El lienzo peor conservado es el SE, que apenas se eleva un metro del suelo aunque pudiera tener parte de su alzado enterrado entre sus propios escombros. Sin embargo, en el resto, quedan importantes vestigios y conservan gran parte del enlucido exterior, aunque el interior se ha perdido por completo.

En las cuatro esquinas del rectángulo se adosan otras tantas torres cuadradas del mismo material y $4 \mathrm{~m}$ de lado. Se conserva completa la planta de las torres orientadas al $\mathrm{E}$ y al $\mathrm{O}$ y restos de las otras dos. En la esquina oriental hay restos de incisiones estriadas en el enlucido del tapial que 
quedarían tapadas por la torre adosada en ese ángulo y que se practicarían para el mejor agarre de la obra adosada. En mitad del paño SE, uno de los mayores y el peor conservado, también es posible apreciar restos de una quinta torre rectangular cuyas medidas son $6,15 \mathrm{~m}$ por $4,75 \mathrm{~m}$, seguramente habitable dadas sus proporciones. Es probable que en la parte central del lado NO, el opuesto al anterior, estuviera situada la puerta de acceso, aunque no es posible determinarlo con certeza. La hipótesis se establece por eliminación, ya que en los lados menores las estructuras emergentes no permiten observarla y en el SE, se adosa la torre que haría más complicada su apertura.

El tapial calicastrado tiene numerosas lajas de esquistos de gran tamaño en su interior formando tongadas. Muchas son para sujetar las agujas del encofrado, pero otras hiladas intermedias le confieren un aspecto cercano al tapial de cal y cantos visible en Jérez. El mortero es pobre en cal y su color terroso obscuro a causa de los esquistos. El cajón tiene un grosor de 1,35 m, 0,70 de alto y 2,70 de largo aproximadamente. Las agujas están sujetas por lajas de piedra de las que, por su estado de conservación, no es posible medir las dimensiones de las tablillas ni apreciar si tienen cuerdas. A pesar de que algunos mechinales atraviesan los muros de lado a lado, parece debido, al menos en parte, al deterioro del tapial y no a que en origen fuera así. Las tablillas de las torres tienen $15 \mathrm{~cm}$ de ancho por $2,5 \mathrm{~cm}$ de grueso, pero tampoco se ven marcas ni restos de cuerdas. También pueden verse de forma reiterada, en el contacto entre los cajones, las huellas de costales interiores semicirculares, de manera que a cada cajón le corresponde un cuarto de círculo. Estas son posteriormente tapadas con trozos de ladrillo y mortero y enlucidas junto con el resto de la obra.

La fortificación no está en una zona preeminente, ni defendible prácticamente por ninguno de sus flancos. Como hemos dicho, es una obra homogénea, uniestratigráfica, ya que, aunque las torres sean adosadas, lo son seguramente en el mismo momento o muy poco después y están construidas con la misma técnica y materiales. No tiene cerámica en el mortero, ni la hay apenas en el interior y alrededor de sus muros. Sólo hacia el Este, en dirección a Lanteira, encontramos algunos restos más, aunque no son muy significativos, entre ellos fundamentalmente cerámica tardoalmohade o ya plenamente nazarí junto con fragmentos de cerámica moderna. La denominación de castillo del Barrio nos lleva a pensar en la existencia de uno en las inmediaciones, seguramente donde se encuentran las mayores concentraciones de cerámica, junto al pequeño barranco de la Rambla de 
Lanteira. Pero, como decimos, por su situación y estructura nos inclinamos a pensar que pudiera tratarse más de una rábita que de un castillo, aunque la falta de material cerámico nos lleva a pensar en una ocupación no estable.

La denominada como alcazaba de Ferreira está ubicada también en el interior de la población. Se trata de una gran torre cuadrangular, de unos $12 \mathrm{~m}$ de lado, embutida en gran medida entre el caserío de manera que el único lado parcialmente visible desde el exterior es el SO. Tiene este un talud de mampostería de $4 \mathrm{~m}$ de altura, posiblemente un añadido como refuerzo y el resto, hasta los $8,50 \mathrm{~m}$, es obra de tapial calicastrado, aunque no nos ha sido posible determinar si también de cal y cantos, de 1,25 $\mathrm{m}$ de espesor. El interior mide 9,50 por 9,30 m con dirección del lado mayor NE-SO. El acceso se realiza hoy a través de un vano en el lado SE de 1,20 m de anchura con un arco de medio punto en ladrillo. Desde ahí se da paso a una sala cuadrada sin techar que ocupa todo el cuadrante $\mathrm{S}$ de la torre y de la que partía la escalera de subida a la primera planta a 3,40 m de altura. En la zona $\mathrm{N}$ hay tres habitaciones: dos rectangulares a los lados y una cuadrada en el centro, cubiertas por forjados de rollizos y tablazón de madera. Todas las divisiones interiores de la torre son de mampostería.

Fuera de la torre, a unos tres metros y paralelo a ella, hay un aljibe construido con muros de hormigón de cal de $70 \mathrm{~cm}$ de grosor y cubierto con bóveda de cañón de mampostería de lajas. Tiene planta ligeramente trapezoidal y unas dimensiones medias de 9 por $2,15 \mathrm{~m}$ y $3 \mathrm{~m}$ de altura hasta el arranque de la bóveda. El brocal está en el lado S. El aljibe está dentro de la casa llamada "El Palacio" que forma gran parte de la manzana en la que se inserta el torreón. Por el nombre que recibe de alcazaba y por la presencia del aljibe fuera de la torre dentro de dicha casa solariega pensamos que esta se insertaba en un recinto amurallado, seguramente el ocupado hoy por la manzana de casas adosadas a la fortificación. Sería así un pequeño castillo, tal y como lo nombra Idrisi ${ }^{20}$ en el siglo XII, aunque esto no quiere decir que los restos que hoy vemos sean necesariamente de esa época.

A grandes rasgos, la mampostería parece usarse predominantemente en dos momentos diferentes: uno en época altomedieval hasta aproximadamente el siglo $\mathrm{X}$ y otro a partir de mediados del siglo XIV, con el

20 AL-IDRISI, Los caminos de al-Andalus en el siglo XI según "Uns al-Muha'wa-rawd alfura”, ed. y trad. Jassim ABID MIZAL, Madrid, 1989, p. 90. 
programa constructivo del reinado de Muhammad V identificado por Manuel Acién ${ }^{21}$, aunque pudiera tener antecedentes en época de Yusuf I. Este, en principio, sería fácilmente identificable en la mampostería encintada con verdugadas y refuerzo de sillares en las esquinas (en las torres de Jérez del Marquesado por ejemplo), pero es posible que inaugurara una tradición de construcción en piedra que sustituye al tapial en las últimas fases de las fortalezas muy en relación con las nuevas técnicas bélicas, es decir, con el uso de la artillería. Así ocurre, sin duda, en Alquife, donde como hemos visto que se superpone al tapial calicastrado y en el que no es posible ver el tipo constructivo descrito sino una mampostería concertada con un llagueado en vitolas decorada en parte con mineral de hierro. Lo mismo ocurriría en Jérez, donde también la mampostería — concertada pero no encintada-, es claramente posterior al tapial calicastrado de cal y cantos. Este hecho vendría reforzado además por la cerámica de superficie, especialmente la escasa encontrada en el castillo de Jérez, que en ningún caso parece ser anterior a la época almohade. En Alquife, como hemos visto 22 (fig. 8), se distinguen hasta tres fases distintas - cuatro, si como tal entendemos la variante decorativa en la mampostería-, que se corresponden con otras tantas técnicas además del hormigón empleado en el aljibe. La fase de ocupación estable parece iniciarse a final del siglo X o con mayor seguridad ya en el siglo XI, en época taifa. A partir de ahí encontramos un asentamiento ininterrumpido hasta final del reino nazarí a la que debe corresponder la última reforma en mampostería.

Más complejo sería el caso de Aldeire (figs. 6-7 y 10-12), donde encontramos la mampostería en la obra mixta junto con el tapial de tierra de la identificada como primera fase constructiva a partir de la estratigrafía mural y de la cerámica hallada en su relleno; el bastión oriental (M1 y T1) de mampostería apenas concertada con llagueado en vitolas y un pretil y almenado en tapial calicastrado $y$, en el frente $S$, todo un enorme paño de mampostería de lajas no concertada posiblemente asociada a esa primera fase $\mathrm{o}$, como en el caso de T12, a reformas posteriores con tapial calicastrado de cal y cantos. La primera, la de la obra mixta, queda claramente distinguida de la segunda (M1 y T1) tanto por el enfoscado total de la primera y la distinta

21 Ver nota número 11.

22 Ver José Ma MARTÍN CIVANTOS, “Alquife...” (supra n. 17). 
disposición de los mampuestos, como por la diferencia en planta de la línea de muralla, más saliente la del bastión. Este bastión es, sin duda, posterior a esta primera fase pero anterior a la torre de tapial calicastrado que se apoya en él (T2) y que a su vez forraba a otra torre de tapial (T3). El problema estaría entonces en intentar determinar si la mampostería es posterior a la segunda fase de tapial de cal y cantos y calicastrado. A nuestro juicio, efectivamente sería así. En cualquier caso, aquí la mampostería no marca la última fase de la fortificación como en los anteriores, lo cual supone un problema, ya que su ocupación no parece prolongarse después del siglo XIII o primeros decenios del XIV. ¿A qué podría deberse esta obra en mampostería en una época, entre el siglo XII y XIII, en la que en al-Andalus no parece construirse con esta técnica? Más allá de esta fecha no encontramos fragmentos cerámicos lo suficientemente significativos como para poder afirmar la continuidad del asentamiento. Es cierto que hay sobre todo jarritas que pueden incluirse en el s. XIV, pero no encontramos ataifores de esa ni de la siguiente centuria ni marmitas claramente nazaríes o cazuelas con el borde en ala. Tendría por tanto una fecha de abandono muy parecida a la del castillo de la Reina en Lanteira ${ }^{23}$. En nuestra opinión, la torre de tapial calicastrado (T2), sería posterior a la obra mixta de cal y cantos y calicastrado, aunque no sabemos con certeza plena si forra a otra torre (T3) realizada con esta técnica o no. Las dimensiones de las dos torres (T2 y T3) parecen desmentirlo, pero el hecho de que no aparezca mampostería en la interior (T3) y el hallazgo de un fragmento de una jarrita almohade-nazarí, nos induce a pensar que no se trata de una torre de la primera fase de mampostería y tapial de tierra. Además, el pequeño resto de mampostería tomado con un mortero rico en cal encontrado entre la parte superior de esta torre (T3) y el suelo de la habitación de la torre exterior (T2), creemos que estaría asociado a la mampostería del bastión oriental (T1 y M1), por lo que este representaría una fase intermedia entre la torre interior (T3), seguramente perteneciente a la segunda fase de cal y cantos y calicastrado, y la exterior (T2), una última reforma anterior en todo caso al siglo XIV.

23 José Mª MARTíN CIVANTOS, Poblamiento.... (supra n. 13), en prensa. 
A esto debemos añadir el fragmento de tapial calicastrado de cal y cantos sobre mampostería del frente S (T12). Es sin duda significativo, pues debe de corresponder a otra fase más del castillo, aunque por su situación aislada es difícil de poner en relación con el resto de las técnicas y elementos constructivos. Aunque sería difícil de probar, nos inclinamos a pensar que sería una etapa intermedia, que deberíamos asociar a los otros ejemplos de esta técnica en el Zenete: el Castillo del Barrio de Lanteira, aunque no fechado ni clara su función, si construido junto a un barrio (harat) a partir de época almohade y el de Jérez, con una primera ocupación almohade, posiblemente asociada a una también primera fase constructiva con esta técnica. ¿Sería entonces posible hacerlas coincidir en una misma época, la almohade? Por el momento es difícil de determinar mientras no haya una excavación arqueológica, aunque a nuestro juicio nos parece factible.

En el resto de los casos en el que la mampostería aparece se hace aún más complicada su interpretación. Así ocurre en los yacimientos ibéricos o romanos reutilizados en el altomedievo como el Cardal o Alrután, donde sin duda, la mayoría de las estructuras encontradas no son medievales. En el Castillejo de Ferreira y Zamarriche (Dólar) los restos son demasiado escasos y en el Castillo de la Reina (Lanteira), la ocupación es algo más compleja: por la cerámica encontrada en el lugar, podríamos hablar de dos momentos: uno, en época altomedieval, durante el emirato y tal vez a comienzos del califato dentro del proceso de proliferación de pequeños centros en zonas elevadas seguramente asociados a la actividad metalúrgica. Otro, una reocupación en época almohade, en el siglo XII que llega a la centuria siguiente durante la primera etapa del reino nazarí. Por el momento, hasta donde hemos podido observar, la ocupación no se prolonga más allá del final del s. XIII y comienzos del XIV24. Sin embargo, no nos es posible determinar la extensión del poblamiento en esos dos momentos, ni la organización del mismo que, obviamente, no debía ser igual. No hemos detectado reparaciones o reestructuraciones de la fortificación, plasmadas en técnicas constructivas

24 De la misma opinión son Maryelle BERTRAND, José Ramón SÁNCHEZ VICIANA, y Juan Fco. ZUBIAUR MARCOS, "Mines et metallurgies médievales de la Sierra Nevada (region de Guadix, prov. de Grenade). Premieres dones", en Actas de las I Jornadas sobre Minería y tecnología en la Edad Media peninsular (León, 1995). León, 1996, pp. 180-197, pp. 183-184 y 189. Sobre la identificación de este yacimiento ver José Ma MARTÍN CIVANTOS, "Alcázar, una alquería en la cara Norte de Sierra Nevada (Granada)", Edad Media, en prensa. 
distintas - excepto dos restos de muros con mortero de cal, demasiado exiguos y fragmentados que podrían ser restos de un tapial situado sobre la mampostería-, o una superposición estratigráfica de las estructuras emergentes. ¿Quiere esto decir que la fortificación que hoy podemos ver es en su totalidad almohade? ¿Debería, en ese caso, ser de tapial y no de mampostería en piedra seca? ¿O tal vez la ocupación de los siglos XII y XIII no es tan importante como para modificar el poblamiento? Esta última posibilidad parece difícil vista la impronta de otros asentamientos de esta época y la cantidad de cerámica hallada. También cabría la posibilidad no fácil de demostrar, de que se tratara de una construcción mixta del mismo tipo que la primera fase del castillo de Aldeire, realizada con mampostería en la parte inferior $\mathrm{y}$, encima, un tapial de tierra $\mathrm{o}$, más probablemente, calicastrado de cal y cantos, como en el mismo Aldeire aparece (T12) y acabamos de señalar al hablar de una posible cronología almohade. Esta misma técnica mixta la encontramos en el Fuerte de Lanteira cuya datación parece coincidir también ${ }^{25}$.

De los tapiales ya hemos hablado algo. Por lo visto hasta el momento, a partir de la estratigrafía mural y de la cerámica, los primeros deberíamos fecharlos en el siglo X. Así ocurriría por ejemplo en el caso de La Calahorra con el hormigón de la primera fase. A falta de una excavación que lo confirme, este sería el castillo más grande de la comarca ya que seguramente ocupara todo el cerro. Más claro es el caso de Alquife, cuya primera fase de tapial de cal y canto es seguramente del s. XI. En su mortero no aparece cerámica incrustada (en las otras fases sí), ni mineral de hierro o escoria de las contiguas minas, por tanto debería ser de la misma época de fundación. También hemos señalado el uso de esta técnica en la propia Alcazaba de la ciudad de Granada en época taifa, tal y como puede verse en ciertos tramos y como ya afirmara Torres Balbás: "los paños de muralla y las torres intermedias obra de tapia, con cantos gruesos y rodados unidos por dura argamasa"26. Igualmente es claramente visible su empleo el castillo de Qabrira, en el camino de Granada a Guadix, de singular importancia y

25 José Ma MARTÍN CIVANTOS, “Alcázar...” (supra n. 24), en prensa.

26 Leopoldo TORRES BALBÁS, "El alminar..." (supra n. 8), p. 441 y José Ma MARTÍN CIVANTOS, "Alquife..." (supra n. 17). 
claramente fechado en el siglo XI gracias a las memorias del rey 'Abd Allah'27. ¿Podría entonces responder a un programa estatal de construcción que incluyera la creación de importantes fortalezas y/o villas fortificadas como la de Illora también en Granada? De ser así cabría entonces la posibilidad de que los restos hoy visibles del castillo de Huéneja dataran de esa época, lo que en principio también se correspondería con la dinámica del poblamiento y la organización del territorio ${ }^{28}$.

Tampoco hay muchas dudas de que en el mismo castillo de Alquife, las obras realizadas en tapial calicastrado son nazaríes o tal vez almohades por la cerámica incrustada en el mortero. Son, sin embargo, como hemos dicho, anteriores a la mampostería, tal y como ha quedado demostrado estratigráficamente. No sería de extrañar que ambas técnicas fueran incluso próximas en el tiempo. Recordemos, por ejemplo, como en Granada se construye en tapial calicastrado la muralla exterior del Albayzín durante el reinado de Yusuf I (1333-1354)29 mientras su hijo, Muhammad V (13541359/1362-1391) desarrolla inmediatamente después un programa edilicio en mampostería ya descrito. Por otra parte, el deterioro de este castillo es mucho más visible en la parte oriental, la de cal y canto, que en la occidental y son, además, destrozos claramente intencionados tal y como se ve en la disposición vertical de algunos fragmentos de muralla y el socavamiento de la base de mampostería de las dos torres más orientales. A nuestro juicio, esto habría supuesto una reducción del espacio defensivo aún en época andalusí y por tanto la construcción de un nuevo modelo de fortaleza. Volveremos sobre estas cuestiones más adelante.

En Aldeire el tapial de tierra sobre la obra de mampostería también parece corresponder a estas fechas, el siglo XI, tanto por la cerámica como por ser estratigráficamente la primera fase documentada. A partir de aquí tenemos hasta cinco fases en un período de tiempo relativamente reducido (prácticamente tres siglos). La primera, lo hemos visto, es una obra mixta de

27 Antonio MALPICA CUELLO, "Un Hisn en las Memorias del rey 'Abd Allah: ", Revista del Centro de Estudios Históricos de Granada y su Reino, nº 1 (2 época, 1987), pp. 53-68. 28 José Ma MARTÍN CIVANTOS, "Sobre el castillo de Montaire y la pervivencia de los distritos castrales en el s. XI", en Actas del II Simposio de Jóvenes Medievalistas. Lorca (Murcia), 2004, en prensa.

29 Mariano MARTIN GARCÍA, "La muralla exterior del Albaicín o Cerca de Don Gonzalo. Estudio histórico y descriptivo", Cuadernos de Estudios Medievales, XIV-XV (1985-1987), pp. 177-210. 
mampostería y tapial de tierra. Desconocemos a qué puede responder la utilización de una técnica mixta en la segunda fase de cal y canto y calicastrado. Es seguro que el cal y canto es más sólido (también más pesado), y por eso se usa en la parte inferior, pero el calicastrado es probablemente más rápido de hacer. ¿Podría deberse, en el mismo siglo XI, a un momento de emergencia y peligro por las luchas con la taifa almeriense o a comienzos del siglo XII por la incursión de Alfonso el Batallador? En Alquife hemos dado una cronología para el cal y cantos más o menos firme, pero el calicastrado no creemos que se emplee antes del s. XII. El tapial calicastrado de cal y cantos de la torre del lado S (T12) podría corresponder a una fase almohade si atendemos al razonamiento anteriormente expuesto, pero no podemos determinar si sería precedente al bastión oriental de mampostería. Por último, como fase final aparecería la torre de tapial calicastrado (T2) con un rico mortero de color anaranjado que apoya sobre el bastión (M1) y forra otra torre de tapial (T3). Podríamos tal vez fecharla entonces en el siglo XIII o tal vez incluso a comienzos del XIV.

Efectivamente, el tapial calicastrado de cal y cantos creemos poder fecharlo en el s. XII, casi a modo de técnica intermedia entre el cal y cantos del s. XI y el calicastrado ya de plena época almohade y nazarí. En Jérez puede verse gracias a la cerámica más temprana y seguramente así suceda en el castillo del Barrio a juzgar por la evolución del poblamiento circundante. Del castillo de La Reina en Lanteira no tenemos datos, pero por la cronología y por la existencia de una elevada base de mampostería de lajas como en la T12 de Aldeire nos inclinamos a pensar que probablemente fuera este el tapial utilizado en su construcción. Por desgracia, en ninguna de las fortificaciones podemos establecer una relación estratigráfica entre el calicastrado de cal y cantos y el calicastrado.

Igual cronología arroja el tapial calicastrado empleado en Alquife tal y como hemos dicho, aunque las soluciones constructivas en la sujeción de los costales del encofrado son diferentes.

En Dólar, por su parte, podríamos, atendiendo a la estratigrafía mural, distinguir al menos dos fases: una primera correspondiente al aljibe más antiguo a la que nosotros asociamos las obras realizadas en tapial calicastrado, fundamentalmente el muro que se le adosa, pero seguramente también el recinto mayor con las tres torres. Un segundo momento lo ocuparía el segundo de los aljibes, el más moderno, junto con el muro que se le adosa y lo rodea y 
tal vez la estructura de habitación pentagonal. Esta última al menos, tal y como hemos visto, es posterior al paño de tapial calicastrado aunque esto no quiere decir que sea coetáneo al aljibe y a la muralla de hormigón, podría ser también anterior o posterior. El reducido espacio que ocupa la parte superior y su forma regular solo rota por la estructura pentagonal nos llevan a sugerir la posibilidad de que este pequeño recinto pudiera ser un torreón como el de Ferreira o el de Lanteira rodeado por una muralla de un tamaño algo mayor. Respecto a la cronología, la primera referencia escrita que tenemos es Idisi, en el siglo XII ${ }^{30}$, que habla de Dólar como un lugar fortificado famoso por las peras que produce. Igual que ocurriera con Ferreira, en esta época ya encontramos un territorio bien organizado, con una opción económica fundamentalmente agrícola. La cerámica confirma la importancia de la ocupación desde entonces hasta final del reino nazarí, pero también encontramos fragmentos significativos pertenecientes al s.XI, fundamentalmente ataifores con vidriados melados y achocolatados, e incluso anterior, sin que por el momento podamos precisar más. Es posible que la primera fase constructiva pudiera pertenecer al siglo XII, a época almohade. Ya hemos visto como los tapiales calicastrados del Zenete ofrecen en principio una cronología tardía, aunque no se puede asegurar con certeza plena.

Más problemática resulta la caracterización de los tapiales de la Alcazaba de Ferreira y la Fortaleza de Lanteira. En la primera localidad sabemos que existía un castillo en el s. XII. La segunda debe tener una cronología similar a juzgar por lo que ocurre con el poblamiento de este sector ${ }^{31}$.

En cuanto a las plantas se refiere, a primera vista podemos distinguir básicamente dos tipos: uno irregular, que se adapta al terreno y generalmente de un tamaño considerable y otro tendende a una forma rectangular y de dimensiones mucho más reducidas hasta llegar a ser, en alguno de los casos, un simple torreón. Entre las irregulares estarían las fortificaciones altomedievales hasta el siglo X (Alrután, Castillejo de Ferreira o Zamarriche) y, a partir de esta fecha, el castillo de La Calahorra, el de la Caba de Aldeire, el de Alquife y el de Jérez. El primero parece ser de época califal y

30 AL-IDRISI: Los caminos... (supra n. 20), p. 90.

31 José Ma MARTÍN CIVANTOS, “Alcázar...” (supra n. 24), en prensa. 
seguramente dejaría de utilizarse una vez se construyera el de Alquife. Los dos siguientes tienen una cronología similar, el siglo XI para la primera fase, aunque no en su fecha final. Jérez, en cambio, parece ser una fundación del siglo XII con una ocupación continuada hasta final de época nazarí. En Aldeire no se distingue, en principio, una zona de alcazaba, un reducto más fuerte o con carácter claramente militar. En Jérez es clarísimo, y en Alquife también parece existir en el lado occidental pero asociado a las fases posteriores al siglo XI. Esto no quiere decir que este elemento no exista en las dos fortificaciones de época taifa.

Las segundas, las cuadrangulares, están claramente representadas en el Castillo del Barrio de Lanteira, el Fuerte de la misma localidad y la Alcazaba de Ferreira. También Dólar, como acabamos de ver, parece responder a este esquema en sus dos recintos: el superior podría ser un torreón de grandes dimensiones, como en Ferreira y Lanteira, y el inferior un pequeño recinto fortificado alrededor para refugio seguramente no de personas, o no exclusivamente, sino también de ganado. En este sentido, el esquema sería el mismo que para las torres de alquería aunque con unas dimensiones mayores $^{32}$. A nuestro juicio, la Alcazaba de Ferreira y el Fuerte de Lanteira responderían en realidad a esta misma tipología (no necesariamente el recinto fortificado tenía que ser cuadrangular, aunque si es posible que lo fuera en el caso de las alquerías establecidas en los cerros desgajados del macizo de Sierra Nevada, aprovechando las cimas de estas colinas). En el caso de Ferreira, el aljibe contiguo al torreón pero fuera de él, el topónimo "alcazaba" en el callejero y la estructura de la manzana ocupada por una sola casa de grandes proporciones denominada "el Palacio", induce a pensar que así sucede. En Lanteira también parece haber indicios de muralla en las paratas de la ladera del barranco contiguo al pueblo. En Huéneja, los escasos restos visibles, la morfología del cerro del barrio del Castillo y las noticias ofrecidas por Madoz nos llevan a pensar que también en algún momento debió de existir una estructura muy similar: la plaza de Turrión, donde se encuentra el aljibe, debe corresponder precisamente a eso, a un torreón, rodeado por un

32 Mariano MARTÍN GARCÍA, “Torres de alquería de la provincia de Granada”, en III CongresoNacional de Historia de la Construcción, Madrid, 2000, pp. 651-664 y Miguel JÍMENEZ PUERTAS, “Asentamientos rurales en la frontera: las torres de alquería de la tierra de Loja en época nazarí”, en Asentamientos rurales y territorio en el mundo mediterráneo en época medieval (Berja, 2-5 Noviembre de 2000), en prensa. 
recinto amurallado rectangular. A partir de aquí cabría preguntarse si no serían también así el resto de fortalezas establecidas en los ocho pueblos del Zenete a partir del siglo XII o, más probablemente, del XIII.

En Alquife ya vimos cómo las estructuras en tapial calicastrado y mampostería se encuentran exclusivamente en la mitad occidental, la más pequeña y mejor conservada. Aunque aquí también es posible encontrar algún resto de cal y canto, da la impresión de que en un momento determinado (almohade-comienzos de época nazarí), se introducen reformas sólo en este sector continuadas después con mampostería. El espacio resultante de nuevo es de planta casi rectangular y, en su interior, se incluye el aljibe y restos de una división interna, tal vez otro torreón. En La Calahorra son demasiado exiguos los restos dejados en la construcción del castillo-palacio renacentista, pero, como hemos visto, se observa una estructura cuadrangular de grandes dimensiones realizada en tapial de hormigón con restos de calicastrado sobre el. Es posible por lo tanto que se trate de otro torreón y, en este caso, el hormigón en la planta baja indicaría la presencia de un aljibe. En Aldeire, cobraría sentido la presencia del Fuerte en la calle de las Torres, con una estructura similar, una vez abandonado el castillo de la Caba durante el siglo XIII. Sería, obviando el Castillo del Barrio por sus singulares características, la misma situación que en Lanteira una vez abandonado el Castillo de la Reina en las mismas fechas aproximadamente. En Huéneja, la estructura de la manzana de casas que forman el barrio y el cerro del castillo dibujan una planta también rectangular sobre la pequeña pero escarpada colina. En Jérez, por su parte, es comprensible la existencia del castillo dado el papel desempeñado por esta localidad. Aunque no existe una "capital" del Zenete ni conocemos por ahora la organización interna de la comarca a nivel administrativo, Jérez era sin duda el lugar más importante en época nazarí, el más poblado y el más húmedo y con una vega más extensa. En él aún después de la conquista se mantiene un barrio importante llamado Alcázar frente a la actual localidad, por su cercanía o por estar incluso dentro del recinto amurallado. Su sistema defensivo se completa con las tres torres atalaya de mampostería y planta cuadrada, sin duda nazaríes, y posiblemente de mediados del siglo XIV por la técnica constructiva descrita. Al menos una de ellas, la de Alcázar, es habitable y, por sus dimensiones, también debió de serlo el denominado Torreón hoy desmochado. Harían pues, igualmente, función de torre de vega para refugio de la población que trabajara en las zonas de cultivo de la orilla derecha del barranco, desde donde es muy difícil acceder al castillo. 
En conclusión podemos apreciar varios cambios significativos en la organización del territorio a partir de las fortificaciones que habrá que ir, primero comprobando y, cómo no, cotejando con la estructura de poblamiento y el aprovechamiento del medio. En primer lugar, y a falta de un estudio más exhaustivo, los castillos-refugio situados en altura o que reaprovechan estructuras antiguas tienen una fecha de ocupación aproximada hasta el siglo $\mathrm{X}$, coincidiendo con la formación del Estado omeya, es decir, el fin de la fitna y el establecimiento del califato. Es a partir de ahora y durante la centuria siguiente, cuando se produce, según todos los indicios, la primera gran reestructuración del poblamiento con el establecimiento de una red de alquerías y la creación de las grandes vegas de regadío en todos los valles con una nueva orientación del sistema productivo que pasará a basarse fundamentalmente en la agricultura intensiva de regadío ${ }^{33}$. Aparecen entonces grandes fortalezas como la de Aldeire y Alquife, seguramente al amparo o construidas por el Estado zirí en sus luchas contra la taifa de Almería y en un proceso de control del territorio mucho más férreo que el omeya. En la segunda mitad del siglo XII parece haber de nuevo cambios importantes. El Estado almohade parece tener un peso y una presencia mayor que la que tradicionalmente se le ha venido confiriendo. Es entonces cuando se produce la segunda ocupación del Castillo de la Reina de Lanteira, cuando se funda el castillo de Jérez y seguramente cuando comience la construcción de la red de pequeños castillos como el de Dólar, Ferreira o las transformaciones de Alquife. Este proceso de transformación se mantendrá y culminará en los inicios del reino nazarí, con el abandono del Castillo de la Reina y de Aldeire y el establecimiento definitivo de una red de pequeños castillos junto a las alquerías y a las vegas. Sólo la conquista castellana en 1489 y el establecimiento de un señorío concedido al Cardenal Mendoza, conseguirán de nuevo remodelar la organización del territorio del Zenete, creando una capital, La Calahorra, con un nuevo y claro signo del poder señorial visible desde gran parte del marquesado, el castillo-palacio renacentista y con el abandono y seguramente desmantelamiento de las demás fortalezas, fuente en todo caso de peligro, pero innecesarias para el control de una comarca relativamente pequeña y homogénea en su organización.

33 José Ma MARTÍN CIVANTOS, “Transformaciones...” (supra n. 13). 


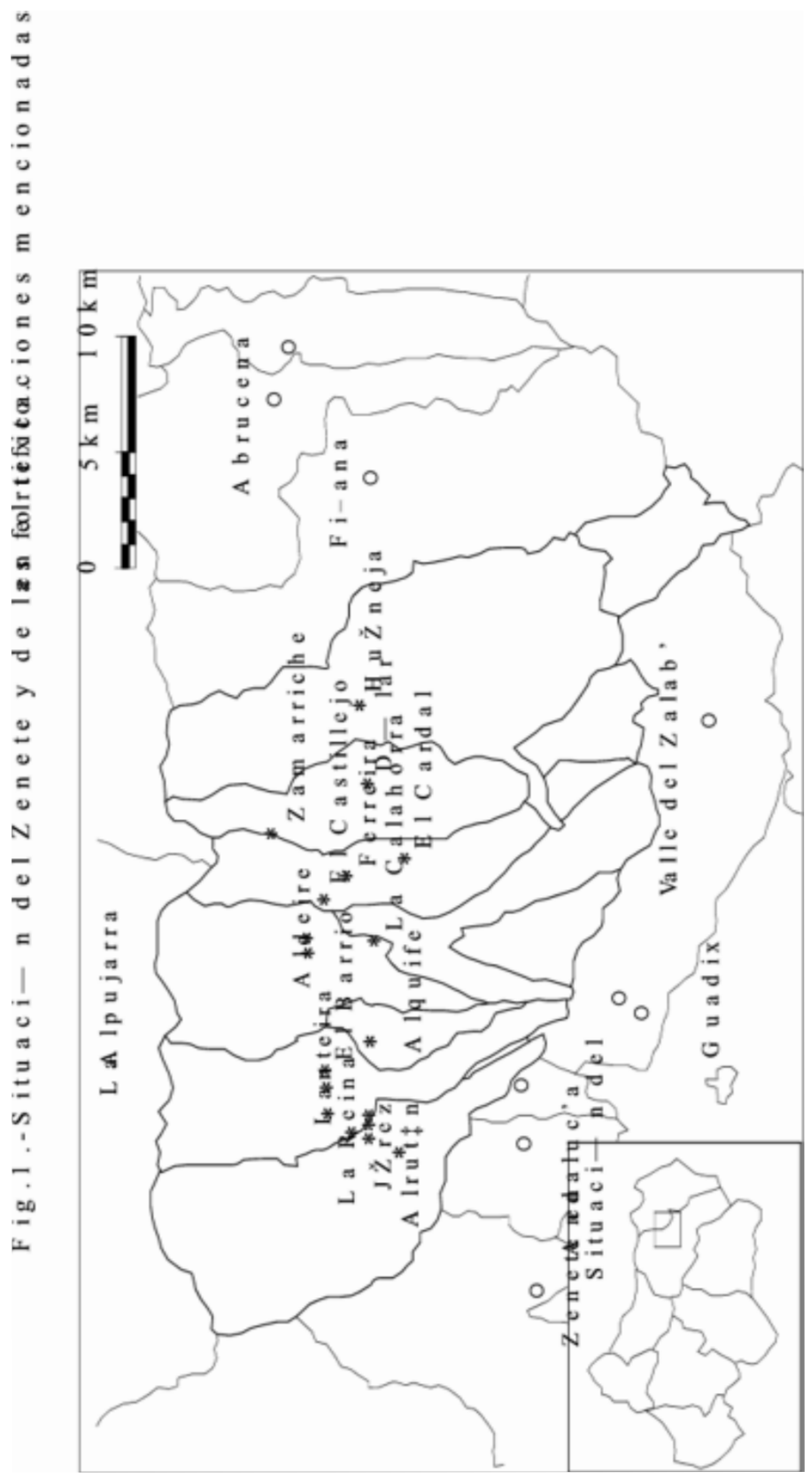

Fig. 1.-Situación del Zenete y localización de las fortificaciones mencionadas 


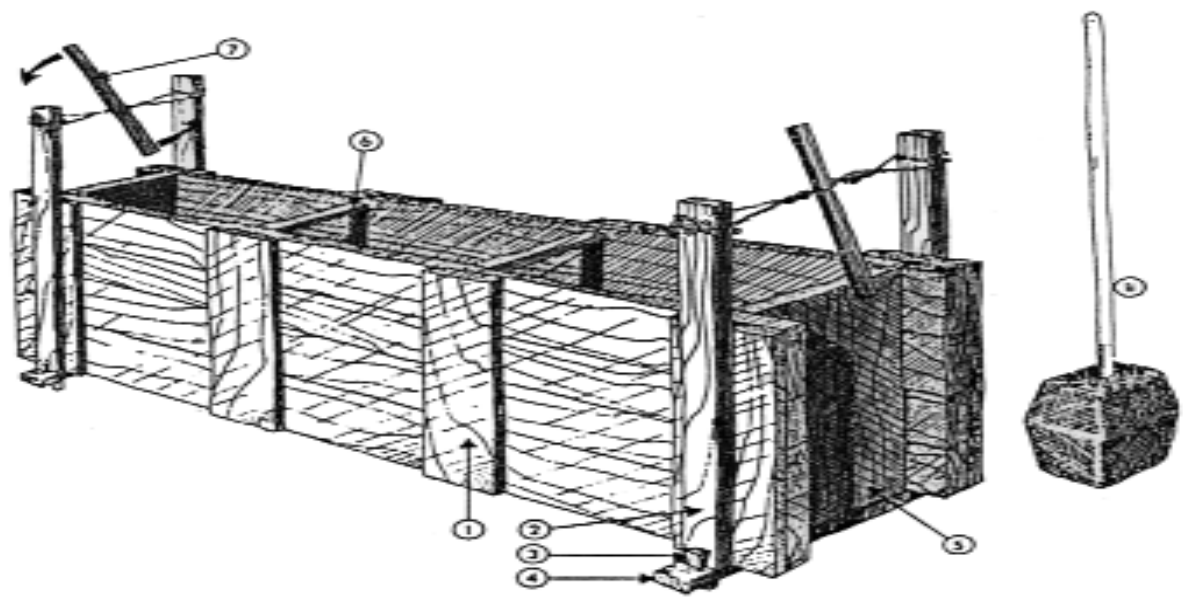

Fig. 2.-Fabricación del tapial:

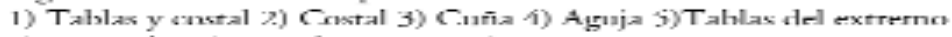

6) Separador 7) Ciucrda y tirante 8) Pissu

Fig. 2.- Construcción del tapial 


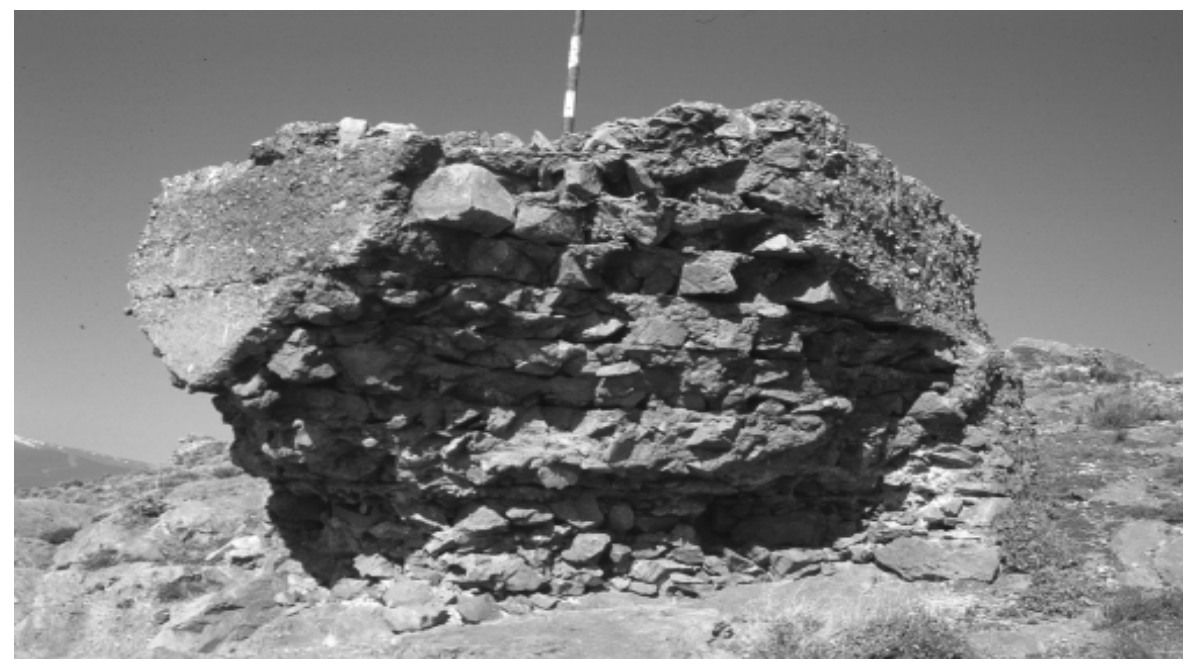

Fig. 3.-Tapial de calicantos. Castillo de Alquife

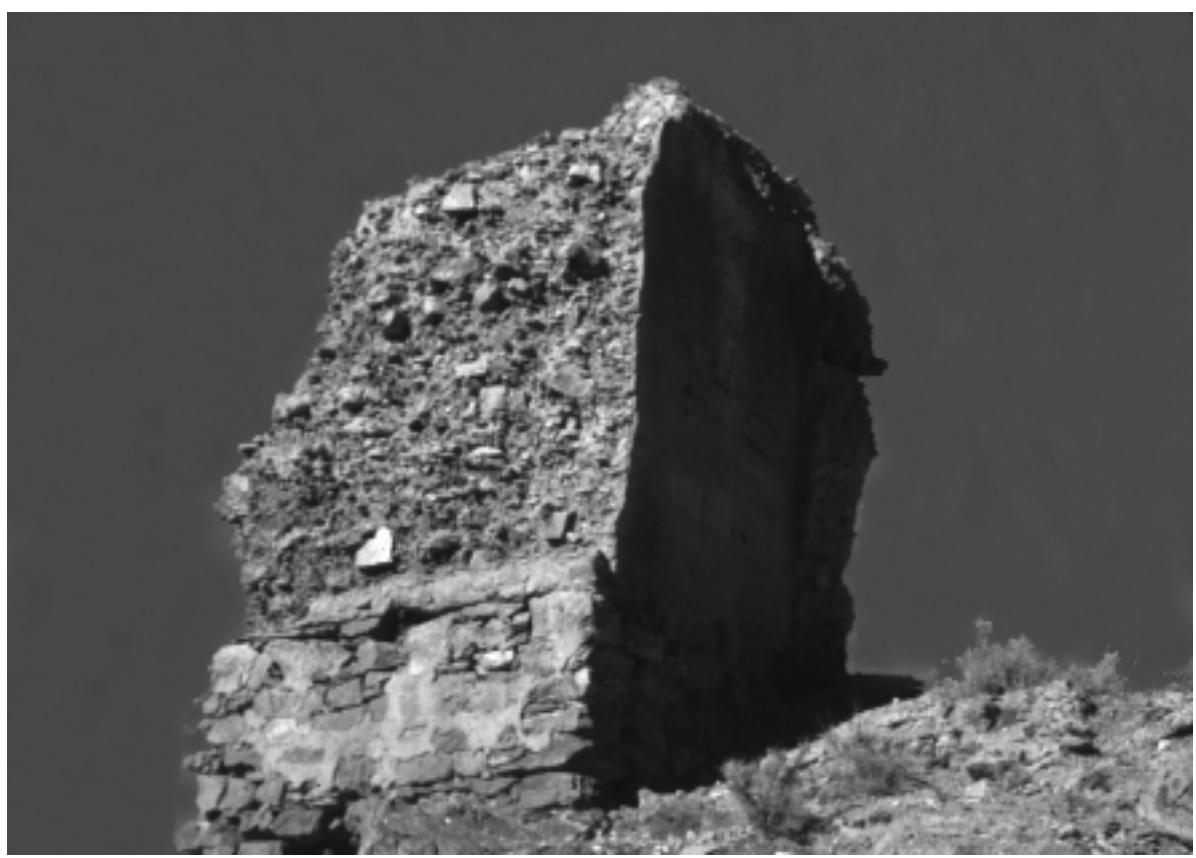

Fig. 4.- Tapial calicastrado. Alquife TSO 


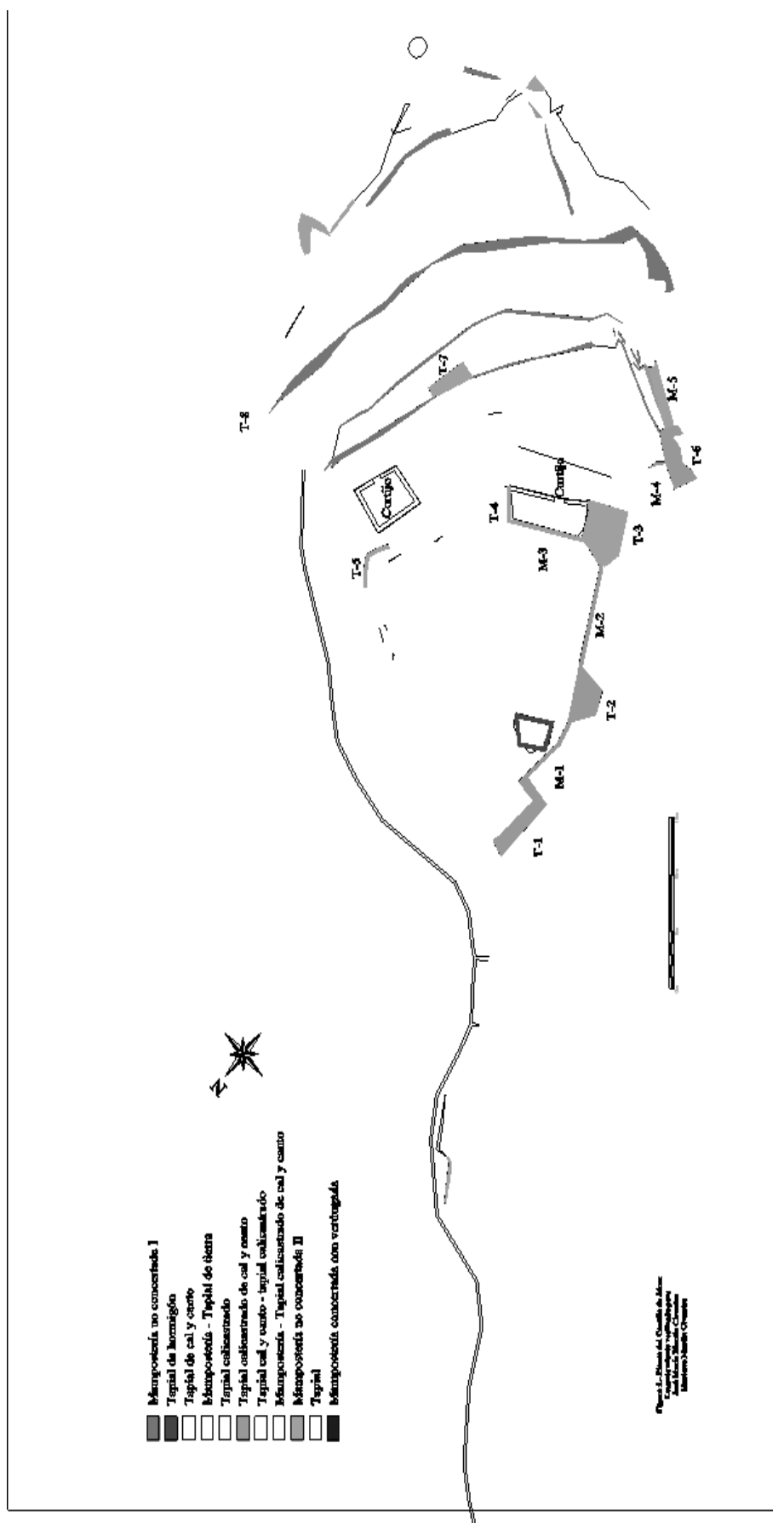

Fig. 5.- Castillo Jérez Planta 

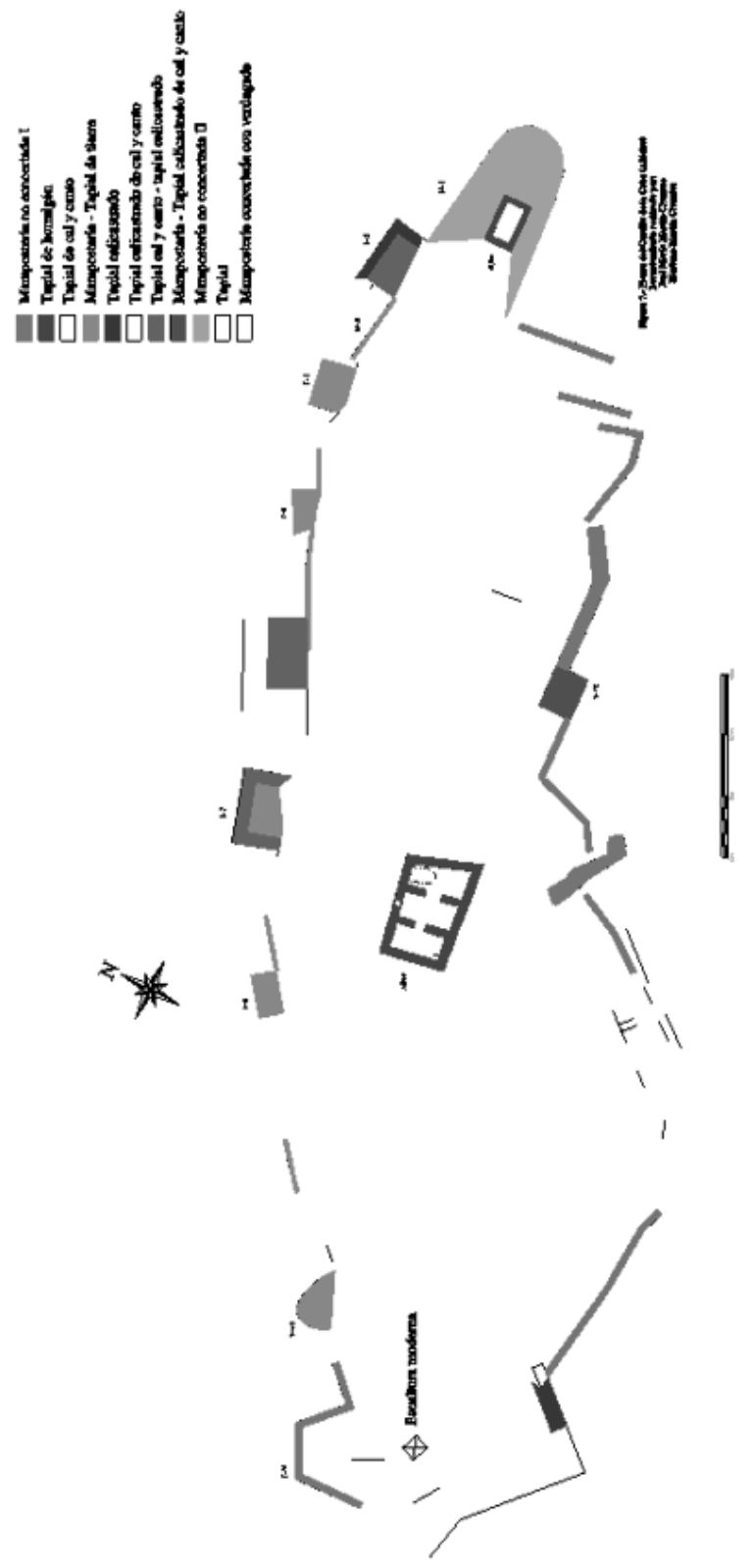

Fig. 6.-Castillo de La Caba (Aldeire). Planta 


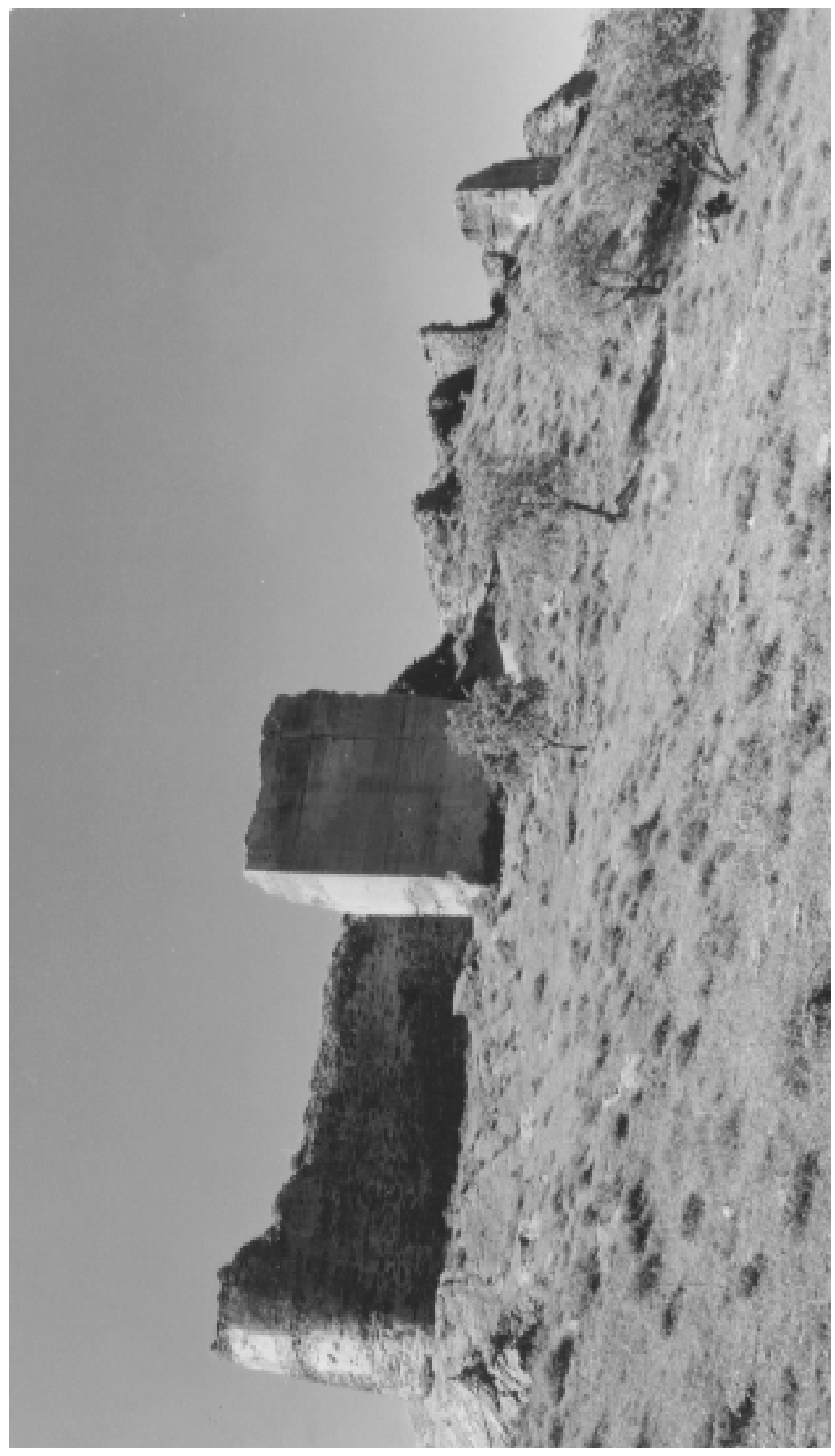

Fig. 7.- Castillo de La Caba. Vista general 

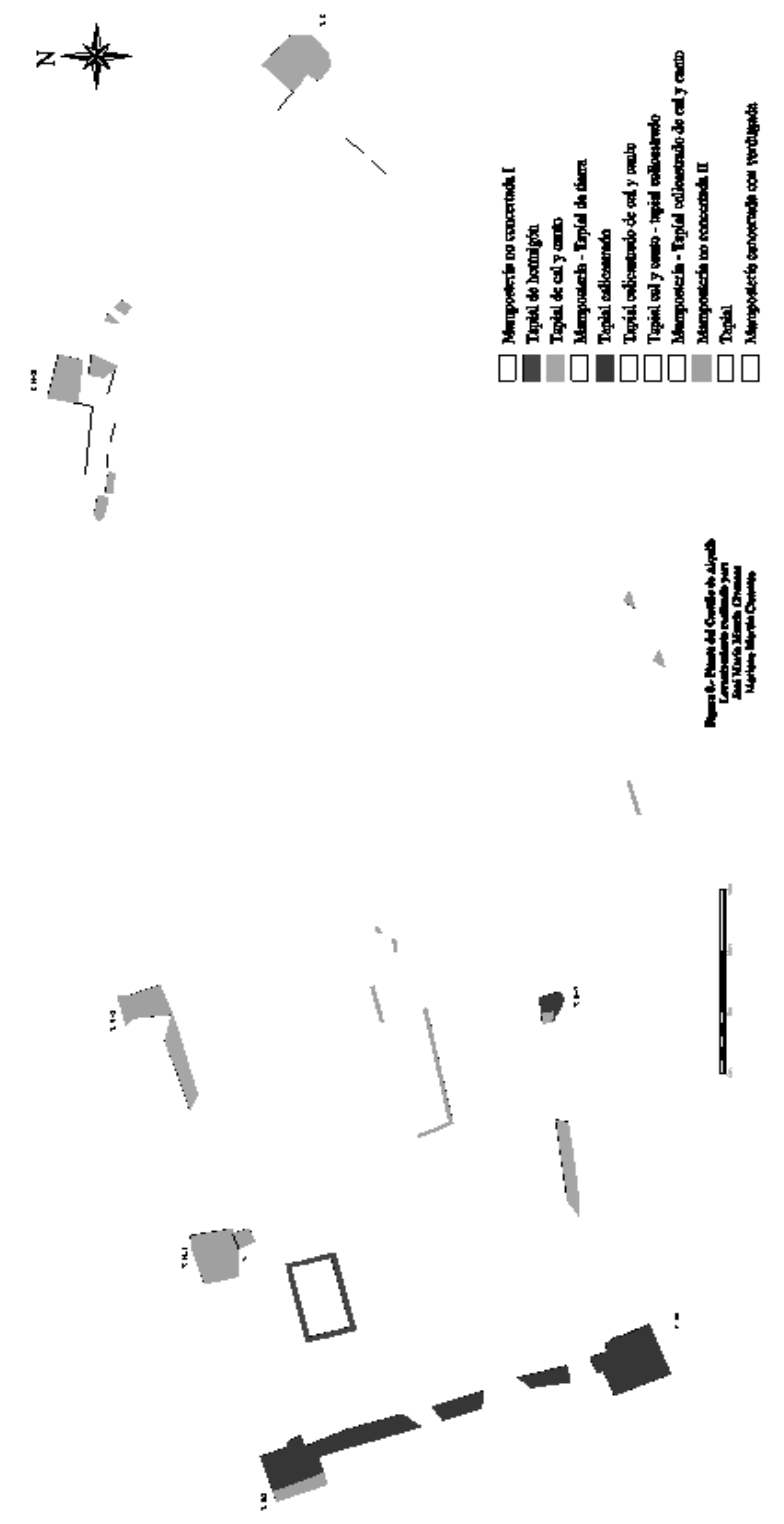

Fig. 8.- Castillo de Alquife. Planta 


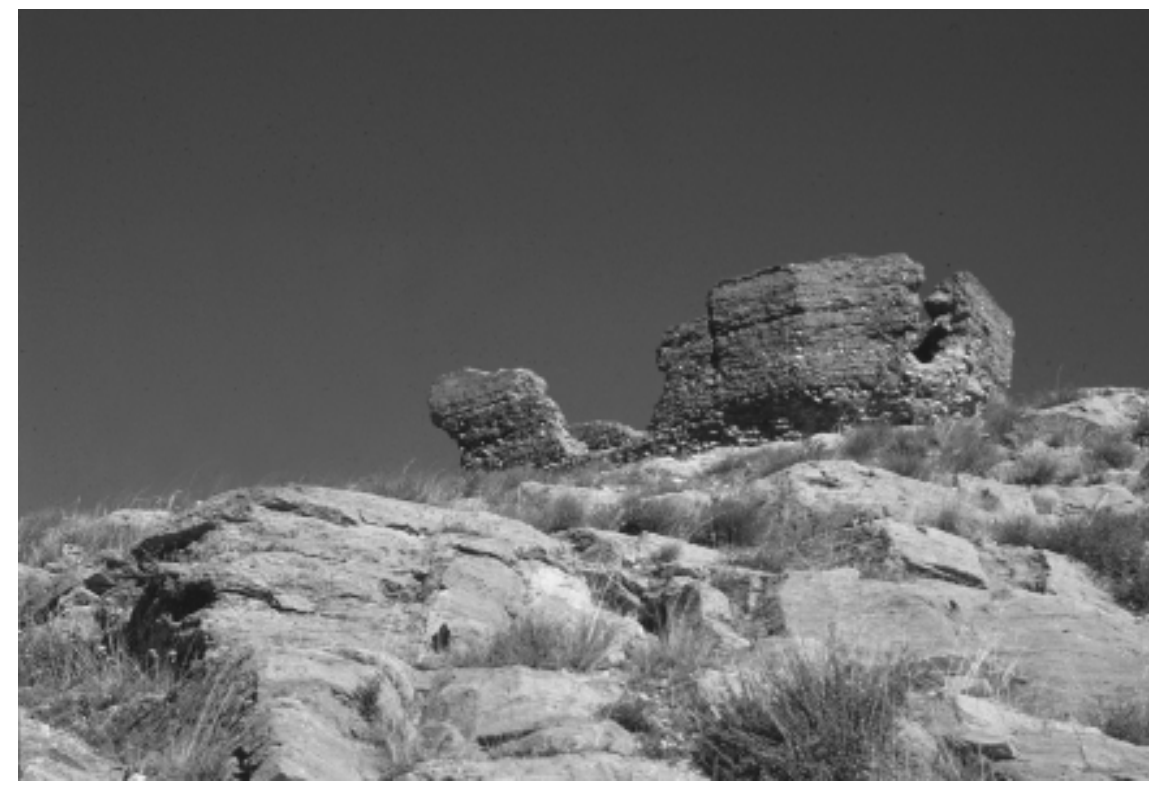

Fig. 9.- Castillo de Dólar. Estructura pentagonal

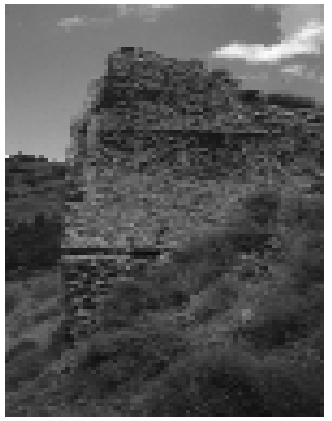

Fig. 10.-Castillo de la Caba (Aldeire) 


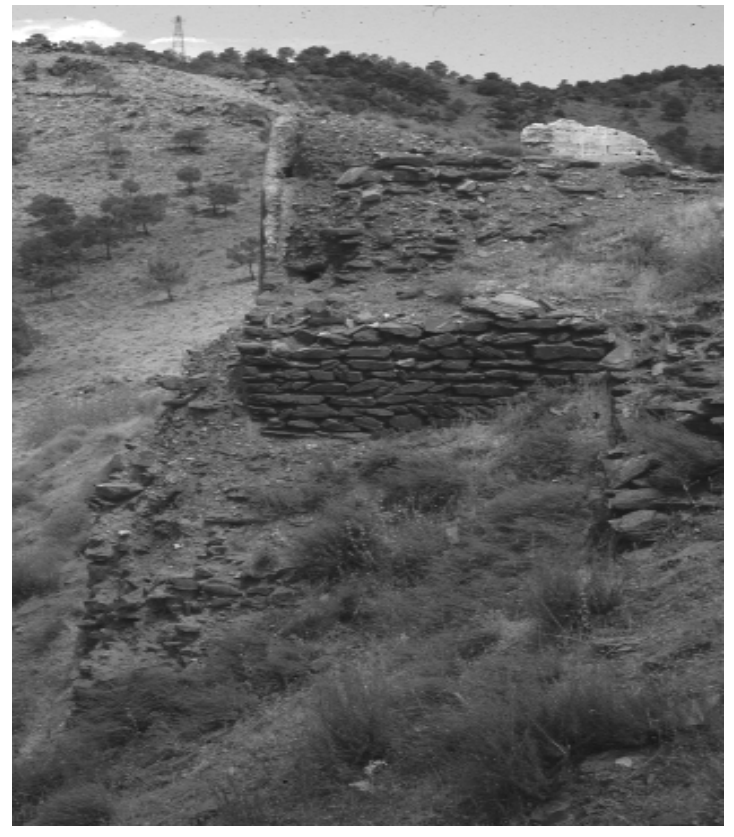

Fig. 11.-Castillo de la Caba (Aldeire).

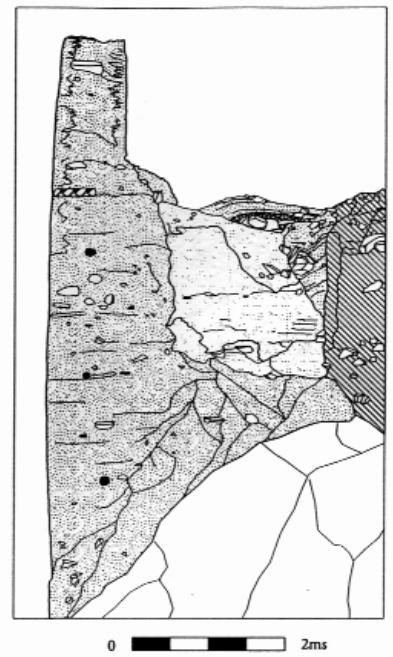

Castillo de Aldeire: La torre 2 (T2) forra a la número 3 (T3) y apoyan sobre M2. Sóbre T3 hay un resto de mamposterfa
seguramente perteneciente a M1

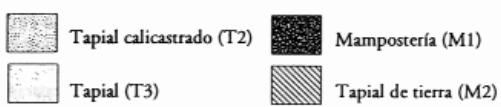

Fig. 12.-Castillo de la Caba (Aldeire). 